Pecvnia, Monográfico (2009), pp. 347-400

\title{
Las combinaciones de negocios
}

José Miguel Fernández Fernández

jose-miguel.fernandez@unileon.es Universidad de León

Fac. de Ciencias Económicas y Empresariales

Campus de Vegazana, $\mathrm{s} / \mathrm{n}$

24071 León (España)

\section{INTRODUCCIÓN}

El Plan General de Contabilidad aprobado mediante Real Decreto 1514/2007, de 16 de noviembre, incluye en su norma de registro y valoración $\mathrm{n}^{\circ} 19$ el tratamiento contable que hay que dar a las combinaciones de negocios, regulando por primera vez operaciones como las fusiones, escisiones o la adquisición de acciones o participaciones mayoritarias en el capital de una empresa. En realidad, los criterios adoptados proceden de la Norma Internacional de Información Financiera $\mathrm{n}^{\circ} 3$ (en adelante NIIF 3) adoptada por la Unión Europea en diciembre de 2004 y que en la actualidad está sometida a revisión.

En la contabilización de las combinaciones de negocios se opta por la aplicación general del método de la adquisición que supone la incorporación al patrimonio de la entidad adquirente de los elementos de 
activo y pasivo identificables del negocio adquirido por su valor razonable en la fecha de adquisición y la contabilización de la diferencia entre el coste de la combinación y los activos y pasivos así valorados, como un fondo de comercio (si es positiva) o directamente en la cuenta de resultados como un ingreso (si es negativa).

El fondo de comercio resultante de la combinación, que refleja el precio pagado por la adquisición de un conjunto de elementos de carácter intangible que suponen un verdadero valor para la entidad adquirente, pero cuya valoración individual no se puede efectuar, no es susceptible de amortización, debiendo ser sometido, al menos una vez al año, a un test de deterioro para comprobar su posible pérdida de valor, que en todo caso ha de ser considerada como irreversible.

\section{DEFINICIÓN DE COMBINACIÓN DE NEGOCIOS}

El PGC define las combinaciones de negocios como «aquellas operaciones en las que una empresa adquiere el control de uno o varios negocios» mientras que la NIIF 3 las considera como «la unión de entidades independientes o negocios en una única entidad que informa». En ambos casos se está aludiendo a dos aspectos básicos que han de estar presentes en toda combinación, que participen entidades o negocios y que dichas entidades o negocios sean independientes.

Por su parte, se considera que un negocio es un conjunto de elementos patrimoniales constitutivos de una unidad económica dirigida y gestionada con el propósito de proporcionar un rendimiento, menores costes u otros beneficios económicos a sus propietarios o partícipes y control es el poder de dirigir la política financiera y de explotación de un negocio con la finalidad de obtener beneficios económicos de sus actividades.

Generalmente consiste en factores, procesos aplicados a esos factores y los productos resultantes, que se usan para obtener ingresos. Si en el conjunto de activos y actividades transferido está presente un fondo de comercio se presume que dicho conjunto es un negocio (por ejemplo, el segmento banca privada de una entidad de crédito, o bien las actividades realizadas en un país, en el caso de empresas que trabajen con establecimientos y negocios en varios países). 
No se considerará una combinación de negocios cuando una entidad adquiera el control de un conjunto de elementos que no satisfaga las condiciones para ser calificado como un negocio. En estos casos, no se podrá utilizar el método de adquisición para su reconocimiento contable, que es el propio de las combinaciones de negocios, sino que se deberá distribuir el coste de la compra de dicho conjunto entre los activos identificables y pasivos que lo forman sobre la base de sus valores razonables relativos en la fecha de adquisición. No se reconoce fondo de comercio o exceso de coste sobre el valor razonable de los activos netos adquiridos (párrafo 4, NIIF 3).

La NIIF 3 excluye de su alcance las «combinaciones de negocios» entre entidades o negocios bajo control común, que se definen como aquéllas en las que todas las entidades o negocios que se combinan están controlados, en última instancia, por una misma parte o partes, tanto antes como después de que tenga lugar la combinación de negocios, y ese control no tiene carácter transitorio. La razón por la que este tipo de transacciones están excluidas del alcance de la NIIF 3 es porque no cumplen la definición de combinación de negocios. En estas operaciones no surgen nuevas sinergias que justifiquen el reconocimiento contable de un nuevo fondo de comercio, sino que se trata de una operación entre entidades de un mismo grupo que debe ser eliminada en los estados financieros consolidados.

El problema surge cuando la «parte» que controla en última instancia a las entidades o negocios participantes no está obligada a elaborar estados financieros consolidados conforme a las NIC, en particular, cuando dicha «parte» es una persona física o conjunto de personas físicas que actúan sistemáticamente en concierto (un ejemplo de grupo de coordinación u horizontal), ya que no existen estados financieros en los que reflejar la eliminación de la operación, de acuerdo con las indicadas normas. Este aspecto va a ser abordado en la segunda fase del proyecto sobre combinaciones de negocios del IASB, ya que, actualmente, en las Normas Internacionales no están obligados a consolidar todos los grupos de entidades, por lo que en algunas ocasiones no se refleja la realidad económica de un conjunto de entidades que actúan como una unidad.

El PGC, sin embargo, si ha regulado las operaciones de fusión, escisión y aportación no dineraria de un negocio entre empresas del grupo, distinguiendo entre aquellas en las que intervienen la empresa dominante del grupo, o la dominante de un subgrupo, y su dependiente, y 
las realizadas entre otras entidades del grupo. En las primeras, los elementos constitutivos del negocio adquirido se valorarán por el importe que correspondería a los mismos en las cuentas anuales consolidadas del grupo o subgrupo según las Normas para la Formulación de las Cuentas Anuales Consolidadas (sin modificar los valores contables de los elementos patrimoniales de la empresa dominante); en las segundas, los elementos patrimoniales del negocio adquirido se valorarán según los valores contables existentes antes de la operación en sus cuentas anuales individuales, registrándose en una partida de reservas las diferencias que pudieran ponerse de manifiesto por la aplicación de los criterios anteriores.

\section{MÉTODOS DE CONTABILIZACIÓN DE LAS COMBINACIONES}

\section{DE NEGOCIOS}

Las combinaciones de negocios pueden estructurarse de muy diversas formas, pudiendo distinguirse en función de la forma jurídica empleada, los siguientes tipos:

a) La fusión o escisión de varias empresas.

b) La adquisición de todos los elementos patrimoniales de una empresa o de una parte que constituya uno o más negocios.

c) La adquisición de las acciones o participaciones en el capital de una empresa, incluyendo las recibidas en virtud de una aportación no dineraria en la constitución de una sociedad o posterior ampliación de capital.

d) Otras operaciones o sucesos cuyo resultado es que una empresa, que posee o no previamente participación en el capital de una sociedad, adquiere el control sobre esta última sin realizar una inversión.

El pago de la combinación puede efectuarse mediante la emisión de instrumentos de patrimonio, la transferencia de efectivo, equivalentes de efectivo u otros activos, o bien una combinación de los anteriores. Además, la combinación de negocios puede suponer el establecimiento de una nueva entidad que controle las entidades combinadas o los activos netos cedidos, o bien la reestructuración de una o más de las entidades que se combinan. 
La contabilización de la combinación difiere dependiendo de la modalidad jurídica empleada; así, en las combinaciones de negocios relacionadas en los apartados a) y b) anteriores, se aplicará el método de la adquisición que supone la contabilización por la sociedad adquirente, en la fecha de adquisición, de los activos adquiridos y los pasivos asumidos en una combinación de negocios, así como, en su caso, de la diferencia entre el valor de dichos activos y pasivos y el coste de la combinación de negocios. En cambio, en las combinaciones de negocios a que se refieren las letras c) y d) anteriores, la empresa inversora, en sus cuentas anuales individuales, valorará la inversión en el patrimonio de otras empresas del grupo conforme a lo previsto para dichas empresas en la norma relativa a instrumentos financieros. En las cuentas anuales consolidadas, estas combinaciones de negocios se contabilizarán de acuerdo con lo que dispongan las normas de consolidación aplicables, normas que prescriben la aplicación general del método de la adquisición (párrafo 6, NIIF 3).

La NIC 22, norma que regulaba las combinaciones de negocios antes de la entrada en vigor de la NIIF 3 , disponía que las combinaciones de negocios en las que no pudiera identificarse a una entidad adquirente, las «fusiones entre iguales», debían contabilizarse de acuerdo con el método de unión de intereses, por el que se agregaban los activos y pasivos de las entidades combinadas por su valor en libros, no pudiendo reconocerse un fondo de comercio como consecuencia de la combinación. Sin embargo, el Consejo de Normas Internacionales de Contabilidad (IASB), en la NIIF 3, eliminó esa opción basándose en el argumento de que permitir dos métodos de contabilización diferentes para las combinaciones de negocios vulneraba la comparabilidad de los estados financieros, permitiendo que transacciones sustancialmente similares se pudieran reconocer contablemente mediante distintos métodos y creando incentivos para estructurar las operaciones de tal manera que se obtuviera el resultado contable deseado. Además, las «fusiones entre iguales», son casos excepcionales de combinaciones de negocios, ya que en su mayoría es posible identificar a una entidad adquirente y no es posible disponer de criterios rigurosos y precisos para distinguir las «fusiones entre iguales» de las transacciones en las que una de las entidades adquiere el control de otra u otras entidades o negocios.

Por último hay que indicar, que las empresas que se extingan en la combinación de negocios, deberán registrar el traspaso de los activos y pasivos, cancelando las correspondientes partidas de activo y pasivo así como las partidas de patrimonio neto. 


\section{EL MÉTODO DE LA ADQUISICIÓN}

De acuerdo con la norma de registro y valoración $\mathrm{n}^{\circ} 19$ del PGC y el párrafo 14 de la NIIF 3, el método de adquisición es el que obligatoriamente se tiene que aplicar en todas las combinaciones de negocios; Dicho método consta de la aplicación de las siguientes etapas:

a) Identificar la empresa adquirente;

b) Determinar la fecha de adquisición;

c) Cuantificar el coste de la combinación de negocios;

d) Valorar los activos identificables adquiridos y los pasivos asumidos; $\mathrm{y}$

e) Determinar el importe del fondo de comercio o de la diferencia negativa.

Seguidamente se analiza cada una de ellas.

\subsection{Identificación de la entidad adquirente}

Todas las combinaciones se contabilizan de acuerdo con el método de adquisición, y para su aplicación es imprescindible la identificación de la entidad adquirente.

La entidad adquirente es aquella participante que, en la fecha de adquisición, obtiene el control del resto de entidades o negocios participantes en la combinación. Se considerará también empresa adquirente a la parte de una empresa, constitutiva de un negocio, que como consecuencia de la combinación se escinde de la empresa en la que se integraba y obtiene el control sobre otro u otros negocios. Cuando se constituya una nueva empresa, se identificará como entidad adquirente a una de las empresas o negocios que participen en la combinación y que existían con anterioridad a ésta.

En la práctica pueden surgir dificultades para identificar a la entidad adquirente en una combinación de negocios; en estos casos de adquisiciones inversas, para identificar la empresa adquirente se atenderá a la realidad económica y no sólo a la forma jurídica de la combinación de negocios. Como regla general, se considerará como empresa adquirente la que entregue una contraprestación a cambio del negocio o negocios adquiridos. Cuando existan dificultades para identificar a la entidad 
adquirente en una combinación de negocios, se analizarán, entre otros, los siguientes aspectos:

- Tamaño de las entidades participantes en la combinación: la de mayor valor razonable probablemente sea la adquirente.

- Personas encargadas de la administración de la entidad resultante de la combinación: la adquirente probablemente sea aquella en la que los directivos tengan la posibilidad de designar el equipo de dirección del negocio combinado.

- Otros factores en combinaciones múltiples: si en la combinación de negocios participan más de dos empresas o negocios, se considerarán otros factores, tales como cuál es la empresa que inició la combinación o si el volumen de activos, ingresos o resultados de una de las empresas o negocios que se combinan es significativamente mayor que el de los otros.

En las NIIF 3 se presume que, en una combinación de negocios, una entidad ha obtenido el control sobre otra, cuando se dé alguna de las siguientes circunstancias:

1) Adquiera más de la mitad del poder de voto de esa otra entidad, salvo que se pueda demostrar claramente que tal propiedad no constituye control.

2) No adquiera más de la mitad del poder de voto de esa otra entidad, pero, como consecuencia de la combinación, disponga:

- De poder sobre más de la mitad de los derechos de voto, en virtud de un acuerdo con otros inversores.

- Del poder para dirigir las políticas financieras y de explotación de la entidad, según una disposición legal, estatutaria o por algún tipo de acuerdo.

- Del poder para nombrar o revocar a la mayoría de los miembros del consejo de administración u órgano de gobierno equivalente.

- Del poder para emitir la mayoría de los votos en las reuniones del consejo de administración u órgano de gobierno equivalente.

Las NIIF requieren, por tanto, que la adquirente sea identificada utilizando la definición de control. Con el objetivo de identificar a la adquirente, se considera la relación entre las entidades 
que participan en la combinación. El adquirente puede ser, en algunos casos, la entidad dependiente legalmente (es decir, una adquisición inversa). Tal es el caso de las combinaciones en las que la sociedad adquirente legalmente emite un elevado número de acciones para entregar a los socios de la entidad adquirida legalmente, de modo que los socios procedentes de la entidad adquirida pasan a tener el control de la entidad adquirente legalmente; en estos casos, la entidad adquirida legalmente será la entidad adquirente desde el punto de vista contable.

Cuando como resultado de una combinación de negocios se crea una nueva entidad a partir de dos o más entidades que se fusionan y desaparecen, se considerará como sociedad adquirente una de las que se fusionan.

A la hora de computar los derechos de voto, se ha de tener en cuenta que las opciones de compra sobre acciones, los instrumentos de deuda o de capital convertibles en acciones, los warrants sobre acciones, y otros instrumentos similares, llevan incorporados un derecho que si se ejercita o se convierte aumenta el poder de voto de la entidad o reduce el poder de voto de otra entidad sobre las políticas financieras y de explotación de una tercera entidad. Estos instrumentos llevan incorporados derechos potenciales de voto.

Una entidad controla a otra cuando tiene la capacidad para dirigir sus políticas financieras y de explotación, sin tener en cuenta si el control se manifiesta activamente o es pasivo por naturaleza; y los derechos potenciales de voto dotan de esta capacidad a su poseedor, a no ser que carezcan de fondo económico, o no sean ejercitables o convertibles en el momento que se realiza el análisis. Por tanto, al evaluar si una entidad posee el control de otra se deben considerar, además de los derechos de voto que posee la matriz directa o indirectamente a través de otras filiales, los derechos de voto potenciales de esta última, como opciones de compra, que sean en ese momento ejercitables o convertibles, incluyendo aquellos en posesión de otras entidades (NIC 27.14). Los derechos potenciales de voto deben cumplir dos requisitos para que contribuyan al control de una entidad:

a) Que sean ejercitables en la fecha del análisis, quedando excluidos por tanto, los derechos que solamente se puedan ejercitar en una fecha futura o cuyo ejercicio esté sometido a condiciones futuras. 
b) Que no carezcan de fondo económico: por ejemplo, cuando se fija un precio de ejercicio de tal manera que evita que se ejercite 0 se convierta en cualquier escenario posible. Adicionalmente, se deberán evaluar todos los hechos y circunstancias que afecten a esos derechos, con la excepción de:

- la intención de la dirección de la entidad de ejercitarlos o convertirlos.

- la capacidad financiera de la entidad para ejercitar o convertir el derecho (NIC 27.15).

\section{Ejemplo n ${ }^{0}$ 1.- Identificación de la entidad adquirente en una combinación de negocios}

Las empresas OMEGA y GAMMA llevan a cabo una combinación de negocios en los siguientes términos:

a) Se crea una nueva entidad, denominada TITA, mediante la fusión de OMEGA y GAMMA

b) Los accionistas previos de OMEGA reciben el 65\% de las acciones emitidas por TITA.

c) Los gestores de OMEGA mantienen sus cargos en la sociedad TITA.

e) El valor razonable de los activos netos de OMEGA en la fecha de adquisición era de 2.000.000€.

f) El valor razonable de los activos netos de GAMMA en la fecha de adquisición era de $850.000 €$

\section{Solución.-}

La empresa adquirente es aquella que obtiene el control sobre el negocio o negocios adquiridos. Como regla general, se considerará como empresa adquirente la que entregue una contraprestación a cambio del negocio o negocios adquiridos. En este ejemplo se produce la creación de una nueva entidad que emite acciones para pagar los patrimonios recibidos de las entidades OMEGA y GAMMA. Dado que los accionistas previos de OMEGA mantienen el control sobre la entidad TITA, que los gestores de dicha sociedad se mantienen en su cargo en la entidad resultante de la combinación y que el valor razonable de los activos netos de la entidad OMEGA es significativamente mayor que el de los activos netos de la entidad GAMMA, OMEGA debe ser considerada como adquirente, por lo que los activos, pasivos, y pasivos contingentes de GAMMA, deben ser medidos al valor razonable para su reconocimiento inicial en los estados financieros de la entidad TITA resultante de la combinación. 


\section{Ejemplo $n^{0}$ 2.- Identificación de la entidad adquirente en una combinación de negocios}

Las empresas ALFA y BETA acuerdan llevar a cabo una combinación de negocios en las siguientes condiciones:

a) La sociedad ALFA emite, para los accionistas previos de BETA, nuevas acciones ordinarias, de forma que dichos accionistas alcanzan el 75\% de los derechos de voto de ALFA una vez efectuada la combinación.

b) La mayor parte de los gestores de BETA se incorporan al equipo de dirección de ALFA.

c) El 75\% de los miembros del Consejo de Administración de ALFA después de la combinación de negocios, proceden del Consejo de de Administración de BETA.

d) El valor razonable de los activos netos de BETA en la fecha de adquisición era de 3.000.000€.

e) El valor razonable de los activos netos de ALFA en la fecha de adquisición era de 2.000.000€

\section{Solución.-}

El PGC establece en su norma de registro y valoración no 19 que para identificar la empresa adquirente se atenderá a la realidad económica y no sólo a la forma jurídica de la combinación de negocios. Como regla general, se considerará como empresa adquirente la que entregue una contraprestación a cambio del negocio o negocios adquiridos. En este ejemplo se produce una excepción a esa regla general pues ALFA es la entidad que emite acciones $\mathrm{y}$, sin embargo, BETA ha de ser considerada como la adquiriente a efectos de la aplicación del método de la adquisición, al margen de cuáles sean los términos legales, dado que los accionistas previos de BETA mantienen el control sobre ALFA después de la combinación, BETA presenta unos activos netos con un valor razonable significativamente superior al que presentan los de ALFA y los gestores de BETA se incorporan al equipo de dirección de ALFA. Se trata, por tanto, de una adquisición inversa en la que la adquirida o dependiente legal es la dominante o adquirente contable y la adquirente o dominante legal es la adquirida o dependiente legal.

Ejemplo $\mathrm{n}^{0}$ 3.- Identificación de la entidad adquirente en presencia de derechos potenciales de voto

Las entidades DELTA y VALLE poseen un $75 \%$ y un $25 \%$, respectivamente, de la entidad ROCA. La entidad DELTA vende la mitad de sus derechos de voto a una tercera entidad TAFISA, la cual emite en ese momento opciones de compra sobre dichas acciones, que son adquiridas por la entidad DELTA cuyo precio de ejercicio es igual a la cotización de las acciones en la fecha del contrato más un $5 \%$.

\section{Solución.-}

La situación del grupo después de la operación puede representarse gráficamente del siguiente modo: 


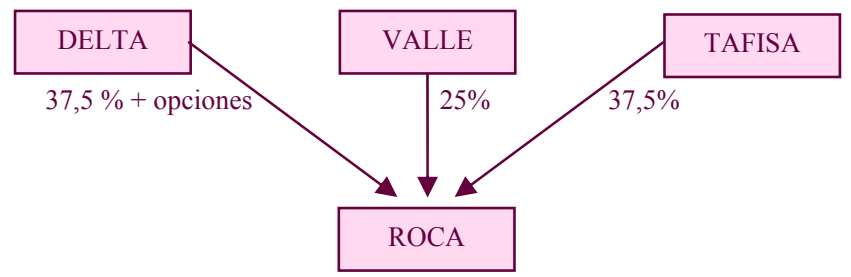

Aunque las opciones de compra sobre las acciones de ROCA que tiene DELTA, tienen un precio de ejercicio mayor que el valor de mercado del activo subyacente, son actualmente ejercitables y dan el poder a la entidad DELTA de continuar fijando las políticas financieras y de explotación de la entidad ROCA. Por eso, se debe considerar la existencia de los derechos potenciales de voto, así como otros factores que determinan la existencia de control. Si estos factores no demuestran lo contrario, la entidad DELTA mantiene el control sobre la entidad ROCA, y por eso ha de ser considerada como la dominante.

\subsection{Fecha de adquisición}

La fecha de adquisición es aquélla en que la entidad adquirente obtiene efectivamente el control sobre la entidad adquirida.

La determinación de la fecha de adquisición es importante, puesto que es el momento en el que adquiere verdadero sentido la determinación del fondo de comercio o de la diferencia negativa de la combinación por comparación entre el coste de la misma y el valor razonable de los activos netos identificables adquiridos. Además, en el caso de que la combinación de negocios conduzca a la formación de un grupo de sociedades, dicha fecha supondrá en inicio del periodo en el que los resultados de la dependiente se integrarán en la cuenta de resultados consolidada.

Cuando se realiza una combinación de negocios en una única transacción de intercambio, la fecha de intercambio es la fecha de adquisición. Cuando una combinación de negocios implica más de una transacción de intercambio, por ejemplo, cuando se realiza en etapas mediante compras sucesivas de acciones, la fecha de intercambio es la fecha en que cada inversión individual se reconoce en los estados financieros de la adquirente. Esas fechas de intercambio se utilizan para determinar la diferencia de la combinación existente en cada una de ellas comparando el coste con la parte proporcional del valor razonable de los activos y pasivos identificables adquiridos. 
Sin embargo, en estas compras por etapas, se considerará como fecha de adquisición, aquélla en que el número de títulos adquiridos proporciona el control a la dominante sobre la entidad dependiente (fecha de la transacción en la que se supera el control sobre más del $50 \%$ de los derechos de voto), pues a partir de ese momento cuando la entidad adquirente ostenta el poder de dirigir las políticas financieras y de explotación de la entidad, con el fin de obtener beneficios de las actividades.

En aquellos casos en que la adquisición esté condicionada a la aprobación por parte de los socios de la entidad adquirente, y la fecha de la junta de accionistas en la que se someta el tema a aprobación sea posterior a la fecha fijada para el intercambio efectivo de acciones, será esa fecha de aprobación la que se considerará como fecha de adquisición pues es cuando se produce la transferencia del control sobre la entidad adquirida.

En algunos casos, una combinación de negocios no puede concluirse hasta que no se obtenga una aprobación del organismo regulador correspondiente. Aunque en la fecha de adquisición la adquirente puede tener el poder de dirigir las políticas de explotación y financieras de la adquirida, no significa necesariamente que la transacción se haya completado legalmente. Es necesario considerar la naturaleza de la aprobación del regulador en cada caso, así como el impacto que tiene en la transmisión del control a efectos de poder establecer la fecha de adquisición.

Cuando se hace una oferta pública de adquisición de acciones, es necesario considerar la naturaleza y los términos de la misma, así como la regulación existente en el país, para la determinación de la fecha efectiva de adquisición y calcular la diferencia de la combinación.

\subsection{Cuantificación del coste de la combinación de negocios}

El coste de una combinación de negocios vendrá determinado por la suma de:

a) Los valores razonables, en la fecha de adquisición, de los activos entregados, de los pasivos incurridos o asumidos y de los instrumentos de patrimonio emitidos a cambio de los negocios adquiridos. 
b) El valor razonable de cualquier contraprestación adicional que dependa de eventos futuros o del cumplimiento de ciertas condiciones, siempre que tal contraprestación se considere probable y su valor razonable pueda ser estimado de forma fiable.

c) Cualquier coste directamente atribuible a la combinación, como los honorarios abonados a asesores legales $u$ otros profesionales que intervengan en la operación.

Cuando la combinación de negocios se lleve a cabo mediante compras por etapas sucesivas el coste de la combinación será la suma de los costes de las transacciones individuales, sin perjuicio del cálculo de la diferencia correspondiente a cada una de las transacciones individuales, como veremos en el apartado correspondiente a las combinaciones de negocios por etapas.

Cuando se difiera la liquidación de la totalidad o una parte del coste de una combinación de negocios, el valor razonable del componente aplazado se determinará descontando los importes a pagar para calcular su valor actual en la fecha de intercambio, teniendo en cuenta cualquier prima o descuento en el que probablemente se incurra en el momento de la liquidación (NIIF 3, párrafo 26) y utilizando para el descuento un tipo de interés de mercado para un instrumento parecido al de un emisor con una calificación crediticia similar.

El coste de una combinación se refiere sólo al coste incurrido para obtener el control sobre la adquirida. Si se incurre en otros costes, deben contabilizarse de acuerdo con los requerimientos del propio PGC. Así, en ningún caso formarán parte, los gastos relacionados con la emisión de los instrumentos de patrimonio (que se deducirán directamente del patrimonio neto) o de los pasivos financieros entregados a cambio de los elementos patrimoniales adquiridos (que son deducidos del importe en libros de la deuda), contabilizándose, por tanto, de acuerdo con lo dispuesto en la norma relativa a instrumentos financieros.

Con carácter general y salvo que exista una valoración más fiable, el valor razonable de los instrumentos de patrimonio o de los pasivos financieros emitidos que se entreguen como contraprestación en una combinación de negocios será su precio cotizado, si dichos instrumentos están admitidos a cotización en un mercado activo. Se entiende que el precio de cotización de un instrumento de patrimonio no es un indicador 
fiable de su valor razonable, sólo cuando su formación se haya visto afectada por la estrechez del mercado. Cuando el precio de cotización sea un indicador poco fiable o no existiese para los instrumentos de patrimonio emitidos por la entidad adquirente, el valor razonable de los mismos deberá estimarse, por ejemplo, por referencia a su participación en el valor razonable de la entidad adquirente o a su participación proporcional en el valor razonable de la entidad adquirida, según cual de los dos sea más claramente evidente (NIIF 3, párrafo 27).

En el coste de la combinación de negocios se incluirán los pasivos incurridos o asumidos por la entidad adquirente a cambio del control de la adquirida. Las pérdidas futuras o los demás costes en que se espere incurrir como consecuencia de la combinación, como los costes de reestructuración de la adquirida, no serán pasivos incurridos o asumidos por la adquirente a cambio del control de la adquirida y, por tanto, no se incluirán como parte del coste.

Cuando un acuerdo de combinación de negocios incorpore algún pago adicional que dependa de eventos futuros o del cumplimiento de ciertas condiciones, la entidad adquirente incluirá el valor razonable de dicho pago futuro en el coste de la combinación, y contabilizará un pasivo por el mismo importe, en la fecha de adquisición, siempre que el pago contingente sea probable y pueda ser valorado de manera fiable.

El ajuste contingente podría, por ejemplo, depender de la consecución o mantenimiento de un nivel específico de resultados en periodos futuros, o de que se mantenga el precio de mercado de los instrumentos que se hayan emitido. El valor razonable de la contraprestación adicional que dependa de eventos futuros o del cumplimiento de ciertas condiciones será ajustado cuando, como consecuencia de circunstancias sobrevenidas, proceda modificar las estimaciones de los importes, se altere la probabilidad de ocurrencia de la contraprestación o cuando se pueda realizar una estimación fiable del valor razonable, no habiendo sido posible realizar ésta con anterioridad. El coste de la combinación se ajusta, en consecuencia, contra el fondo de comercio o el exceso entre el valor razonable de los activos netos y el coste de la combinación, a medida que se revisa la estimación del importe a pagar. No hay periodo límite para realizar los ajustes por contraprestaciones contingentes. Los ajustes pueden surgir como resultado de cambios en las estimaciones, o cuando un importe considerado inicialmente como no probable se convierta en probable y puede ser valorado con fiabilidad. 
Cuando el pago de una contraprestación contingente es diferido, se debe descontar cualquier importe reconocido a su valor presente. El coste de la combinación de negocios no se ajusta por el efecto consiguiente de cualquier descuento; sino que éste se reconoce como un gasto financiero a medida que se devenga.

Los costes directamente atribuibles a la adquisición (tales como los honorarios de contables, asesores legales, registradores, tasadores y otros consultores) forman parte del coste de la combinación de negocios y no incluyen los costes en los que se incurre tras haber obtenido el control, por ejemplo, el coste incurrido para determinar los valores razonables de los activos y pasivos tras la obtención del control. Tales costes son posteriores a la adquisición, dado que se relacionan con la integración de la entidad adquirida, en vez de con la adquisición, y por tanto deben reconocerse como gastos del ejercicio y no se incluirán en los costes de la combinación; lo mismo cabe decir de los gastos de administración general, donde están incluidos los costes de mantener el departamento de adquisiciones, así como de otros costes que no puedan ser directamente atribuidos a esa combinación en particular.

Los costes en los que incurra la entidad adquirida en una combinación de negocios no formarán parte del coste de la combinación, salvo que la adquirente se haya comprometido a reembolsárselos a la adquirida.

Resumiendo, el coste de una combinación de negocios estará constituido por los siguientes componentes:

\begin{tabular}{|l|}
\hline COSTE DE LA COMBINACIÓN \\
\hline + Valor razonable activos entregados \\
\hline + Valor razonable pasivos asumidos \\
\hline + Valor razonable de instrumentos de patrimonio emitidos \\
\hline + Valor razonable de contraprestaciones adicionales que dependan de eventos futuros \\
\hline + Costes directamente atribuibles a la combinación \\
\hline \pm Ajustes del coste en función de sucesos futuros contingentes \\
\hline
\end{tabular}

\section{Ejemplo n ${ }^{0}$ 4.- Determinación del coste de una combinación de negocios}

Las sociedades TAFISA y MEDUSA deciden llevar a cabo una combinación de negocios en las siguientes condiciones: 
1) TAFISA adquiere a la sociedad MEDUSA, completándose la operación el 31-12-X1.

2) TAFISA emite 30.000 acciones nuevas para los accionistas de MEDUSA. En la fecha de la combinación las acciones de TAFISA cotizaban a $2 €$ la acción. Los gastos de emisión de las acciones han ascendido a 2.000€.

3) TAFISA paga $20.000 €$ en efectivo a los accionistas de MEDUSA previos a la combinación.

4) TAFISA se compromete a pagar 30.000€ a plazos del siguiente modo: 10.000€ transcurrido un año desde la fecha de la combinación, 10.000€ transcurridos dos años y otros $10.000 €$ trascurridos tres años. El tipo de descuento que se considera adecuado en este tipo de operaciones es el $5 \%$.

5) TAFISA asume una deuda a corto plazo de 5.000€ que tenía MEDUSA con un cliente en la fecha de la combinación.

6) Si el beneficio medio procedente de los negocios adquiridos a MEDUSA excede de $10.000 €$ por año durante los próximos tres años, TAFISA se compromete a efectuar un pago adicional de $12.000 €$ a los propietarios previos de MEDUSA. En este sentido, MEDUSA históricamente ha tenido beneficios entre 9.000 y $11.000 €$.

7) En el momento de llevar a cabo la combinación de negocios se tiene conocimiento de que un cliente de MEDUSA la ha demandado por incumplimiento de una garantía postventa. El gabinete jurídico de MEDUSA estima que la indemnización que se tendrá que abonar cuando termine el litigio ascenderá probablemente a 5.000€ a satisfacer en el ejercicio X4.

8) TAFISA ha abonado diversos honorarios profesionales (a abogados, tasadores, registradores y asesores) ocasionados por la combinación por importe de $14.000 €$.

9) TAFISA tiene un departamento interno de adquisiciones, que incurrió en $20.000 €$ de costes corrientes durante el periodo en que se completaba la combinación de negocios.

Se pide:

- Determinar el coste de la combinación de negocios para TAFISA.

- Suponiendo que MEDUSA obtiene beneficios por una cuantía de 3.500€ transcurrido el primer año desde la fecha de la combinación ¿sería necesario ajustar el coste de la combinación en estas nuevas circunstancias?

\section{Solución.-}

El coste de la combinación incluirá los siguientes conceptos:

- Valor razonable de los instrumentos de patrimonio emitidos: 30.000 acciones $\times 2 € /$ acción $=$ $60.000 €$.

- Valor razonable de los activos entregados $=20.000 €$.

- Valor razonable de los pasivos asumidos $=5.000 €$.

- Pago aplazado: deberá calcularse el valor actual de los desembolsos futuros, aplicando la tasa de descuento correspondiente, que en este caso es del 5\%. Su importe será:

$$
V A=\frac{1-\frac{1}{(1+0,5)^{3}}}{1,05} \times 10.000=\frac{(1+0,5)^{3}-1}{0,05 \times(1+0,05)^{3}} \times 10.000 \approx 27.232,48
$$


- Valor razonable de la contraprestación adicional que depende de los resultados futuros de los negocios adquiridos a MEDUSA. En las condiciones pactadas parece razonable pensar que es probable que el pago contingente tendrá lugar, y como el montante de $12.000 €$ es susceptible de cuantificación fiable, el valor actual de esos $12.000 €$ se incluirá en el coste de la combinación.

$$
V A=\frac{12.000}{(1+0,05)^{3}}=10.366,05
$$

- Valor razonable del pasivo contingente puesto de manifiesto en la combinación de negocios vinculado a la indemnización previsible como consecuencia de la demanda de un cliente de MEDUSA por incumplimiento de una garantía postventa. El valor razonable de este elemento contingente del coste será el valor actual del pago futuro previsto.

$$
V A=\frac{5.000}{(1+0,05)^{3}}=4.319,19
$$

- Costes directamente atribuibles a la combinación: Pago de los honorarios profesionales = $14.000 €$

- Los gastos derivados de la emisión de los instrumentos de patrimonio (2.000€) no formarán parte del coste de la combinación y serán tratados conforme a lo que el PGC establece en la norma relativa a instrumentos financieros (se deducirán del importe recibido en la ampliación de capital).

- Los $20.000 €$ de gastos del departamento de adquisiciones tendrán la consideración de gastos en el momento en el que el sujeto resultante de la combinación incurra en ellos, pero nunca formarán parte del coste de la combinación (párrafo 29, NIIF 3).

\begin{tabular}{|c|c|}
\hline Valor razonable de las acciones emitidas & $60.000,00$ \\
\hline Valor razonable de los activos entregados .. & $20.000,00$ \\
\hline Valor razonable de las deudas asumidas . & $5.000,00$ \\
\hline Valor razonable del pago aplazado ................. & $27.232,48$ \\
\hline Valor razonable del pago contingente en función de resultados ..... & $1.366,05$ \\
\hline Valor razonable del pasivo contingente por demanda & $4.319,19$ \\
\hline 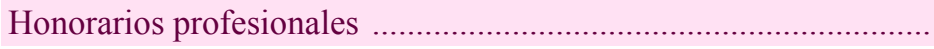 & $14.000,00$ \\
\hline Total coste de la combinación ....... & 131.917, \\
\hline
\end{tabular}

Resumiendo, el coste de la combinación de negocios será el siguiente:

4.4. Valoración de los activos identificables adquiridos y de los pasivos y pasivos contingentes asumidos

En la fecha de adquisición, los activos identificables adquiridos y los pasivos asumidos (incluidos los contingentes) se registrarán, con carácter general, por su valor razonable siempre y cuando dicho valor razonable pueda ser medido con suficiente fiabilidad, con la excepción de 
los activos no corrientes mantenidos para la venta que se reconocerán por su valor razonable menos los costes de venta correspondientes.

Para que los activos y pasivos identificables de la entidad adquirida puedan ser registrados en los estados financieros de la entidad adquirente han de cumplir estrictamente con la definición que el PGC da a cada uno de esos elementos, a saber (NIIF 3, párrafo 37),

(a) en el caso de un activo distinto de un activo intangible, si es probable que la adquirente reciba los beneficios económicos futuros relacionados con el mismo, y su valor razonable se pueda medir de forma fiable;

(b) en el caso de un pasivo no contingente, si es probable que la salida de recursos para liquidar la obligación incorpore beneficios económicos, y su valor razonable se pueda medir de forma fiable;

(c) en el caso de un activo intangible o un pasivo contingente, si sus valores razonables pueden ser medidos de forma fiable.

Si la entidad adquirente no obtiene la totalidad de los derechos de voto de la adquirida, la parte correspondiente a los minoritarios de los valores razonables reconocidos en los activos, pasivos y pasivos contingentes identificables en la adquirida se asignan a los intereses minoritarios.

En los pasivos reconocidos, dentro de la contabilización por el método de adquisición, se excluyen aquellos que surgen por las intenciones de la entidad adquirente o por acciones futuras, por ejemplo los costes de reestructuración de la adquirida ${ }^{1}$. También se excluyen las pérdidas futuras y otros costes en los que se incurrirá como resultado de la adquisición.

Los pasivos por reestructuración se reconocen en la adquisición sólo cuando representan un pasivo ya reconocido por la adquirida en la fecha de adquisición. Un plan de reestructuración de la adquirida que esté condicionado a la adquisición no es, inmediatamente

1 Salvo cuando la adquirida tenga reconocido previamente un pasivo por reestructuración en sus estados financieros conforme a lo establecido en la norma de valoración del $\mathrm{PGC} \mathrm{n}^{\circ} 15$ relativa a provisiones y contingencias. 
antes de la combinación de negocios, una obligación actual de la adquirida, ni tampoco un pasivo contingente.

En la medida en que los ajustes al valor razonable, reconocidos como parte de la contabilización por el método de adquisición, dan lugar a diferencias temporarias, se reconocen impuestos diferidos. Sin embargo, no se reconoce un pasivo por impuestos diferidos en la medida que surja del reconocimiento inicial del fondo de comercio. Dado que el exceso entre el valor razonable de activos netos adquiridos y el coste de la combinación de negocios, se reconoce en resultados inmediatamente, no se contabiliza un activo por impuestos diferidos.

El PGC establece algunas reglas específicas en la valoración y registro de los activos adquiridos y pasivos asumidos:

1. Los activos no corrientes que se clasifiquen como mantenidos para la venta de acuerdo con lo establecido al respecto en la norma correspondiente a estos activos, se reconocerán por su valor razonable menos los gastos de venta ${ }^{2}$.

2. Los activos y pasivos por impuesto diferido se valorarán por la cantidad que se espere recuperar o pagar de la autoridad fiscal, según los tipos de gravamen que vayan a ser de aplicación en los ejercicios en los que se esperen realizar los activos o pagar los pasivos, a partir de la normativa en vigor o que se haya aprobado y esté pendiente de publicación, en la fecha de adquisición. Los activos y pasivos por impuesto diferido no deben descontarse, de acuerdo con lo dispuesto en la norma relativa a impuestos sobre beneficios.

3. Si en la fecha de adquisición, el negocio adquirido mantiene un contrato de arrendamiento operativo en condiciones favorables o desfavorables respecto a las condiciones de mercado, la empresa adquirente ha de reconocer, respectivamente, un inmovilizado intangible o una provisión.

\footnotetext{
2 Por ejemplo, el valor razonable de un inmueble propiedad de la entidad adquirida, y ocupado por ella como oficinas centrales, es de $100.000 €$. La adquirente tiene espacio suficiente en sus propias oficinas centrales para gestionar los negocios adquiridos, y decide que el inmueble de la adquirida sea desalojado y vendido tras la combinación de negocios. Los costes de enajenación (por ejemplo, comercialización y honorarios legales) ascienden a 5.000€. Si el inmueble se clasifica en la fecha de la combinación como mantenido para la venta, debería reconocerse a su valor razonable menos los costes de venta, es decir por $95.000 €$, en la contabilización por el método de adquisición.
} 
4. Los activos y pasivos asociados a planes de pensiones de prestación definida se contabilizarán, en la fecha de adquisición, por el valor actual de las retribuciones comprometidas menos el valor razonable de los activos afectos a los compromisos con los que se liquidarán las obligaciones. El valor actual de las obligaciones incluirá en todo caso los costes de los servicios pasados que procedan de cambios en las prestaciones o de la introducción de un plan, antes de la fecha de adquisición.

5. En ningún caso se registrarán los inmovilizados intangibles identificados cuya valoración no pueda ser calculada por referencia a un mercado activo, si ello originase la contabilización de un ingreso en la cuenta de pérdidas y ganancias (diferencia negativa de la combinación).

Los activos y pasivos reconocidos por la empresa adquirente serán los que se reciban y asuman como consecuencia de la operación en que consista la combinación y cumplan la definición de activos y pasivos establecida en el Marco Conceptual de la Contabilidad, con independencia de que algunos de estos activos y pasivos no hubiesen sido previamente reconocidos en las cuentas anuales de la empresa adquirida o a la que perteneciese el negocio adquirido por no cumplir los criterios de reconocimiento en dichas cuentas anuales ${ }^{3}$. En el caso de que el negocio adquirido incorpore obligaciones calificadas como contingencias, la empresa adquirente reconocerá como pasivo el valor razonable de asumir tales obligaciones, siempre y cuando dicho valor razonable pueda ser medido con suficiente fiabilidad.

En cuanto al establecimiento del valor razonable de los activos, pasivos y pasivos contingentes identificables de la adquirida en la fecha de adquisición y al margen de las reglas específicas que contempla el PGC, anteriormente reseñadas, la NIIF 3 en su apéndice B proporciona una serie de indicaciones resumidas en el cuadro siguiente:

3 Por ejemplo, una deducción de impuestos procedente de las pérdidas fiscales de la entidad adquirida, que no haya sido reconocida por la misma antes de la combinación de negocios, cumplirá las condiciones para su reconocimiento como activo identificable, de acuerdo con el párrafo 36, si es probable que la entidad adquirente vaya a tener, en el futuro, ganancias fiscales contra las que aplicar la deducción por impuestos no reconocida (NIIF 3, párrafo 44). 


\begin{tabular}{|c|c|c|}
\hline Elemento & & Valor razonable \\
\hline \multirow{3}{*}{ Existencias } & $\begin{array}{l}\text { Productos } \\
\text { terminados }\end{array}$ & $\begin{array}{l}\text { Se valoran a su precio de venta menos los costes de enajenación o disposición } \\
\text { por otra vía, y un margen de beneficios razonable por el esfuerzo de venta a } \\
\text { incurrir por la adquirente }\end{array}$ \\
\hline & $\begin{array}{l}\text { Productos } \\
\text { en curso }\end{array}$ & $\begin{array}{l}\text { Se valoran a su precio de venta menos los costes necesarios para completar la } \\
\text { fabricación, incluyendo los costes de enajenación o disposición por otra vía, y } \\
\text { un margen de beneficios razonable por el esfuerzo de transformación y venta a } \\
\text { incurrir por la adquirente }\end{array}$ \\
\hline & $\begin{array}{l}\text { Materias } \\
\text { primas }\end{array}$ & Se valoran por el coste corriente de reposición \\
\hline \multirow[b]{2}{*}{$\begin{array}{l}\text { Inmovilizado } \\
\text { material }\end{array}$} & $\begin{array}{c}\text { Terrenos y } \\
\text { construcciones }\end{array}$ & Se valoran a su valor de mercado \\
\hline & $\begin{array}{l}\text { Otro } \\
\text { inmovilizado } \\
\text { material }\end{array}$ & $\begin{array}{l}\text { Se valoran a su valor de mercado determinado normalmente mediante tasación. } \\
\text { Si no hubiera evidencia de valor razonable, la adquirente podría necesitar la } \\
\text { estimación del valor razonable utilizando un método de valoración basado en } \\
\text { los ingresos o en el coste de reposición amortizado de un activo similar }\end{array}$ \\
\hline \multicolumn{2}{|l|}{$\begin{array}{l}\text { Activos } \\
\text { intangibles }\end{array}$} & $\begin{array}{l}\text { La entidad adquirente determinará el valor razonable: } \\
\text { (i) por referencia a un mercado activo, o bien } \\
\text { (ii) si no existiera un mercado activo, sobre una base que refleje la cantidad que } \\
\text { la adquirente hubiera pagado por el activo en una transacción realizada en } \\
\text { condiciones de independencia mutua, entre un comprador y un vendedor } \\
\text { interesados y debidamente informados, a partir de la mejor información } \\
\text { disponible }\end{array}$ \\
\hline \multirow{2}{*}{$\begin{array}{l}\text { Instrumentos } \\
\text { financieros }\end{array}$} & $\begin{array}{l}\text { Negociados } \\
\text { en un mercado } \\
\text { activo }\end{array}$ & Valores corrientes de mercado (Cotización en bolsa) \\
\hline & $\begin{array}{l}\text { Que no se } \\
\text { negocien en un } \\
\text { mercado activo }\end{array}$ & $\begin{array}{l}\text { Valores estimados que tengan en consideración variables tales como las ratios } \\
\text { precio-ganancia, los rendimientos por dividendos y las tasas de crecimiento } \\
\text { esperadas de instrumentos comparables de entidades con similares características }\end{array}$ \\
\hline \multirow{2}{*}{$\begin{array}{l}\text { Partidas } \\
\text { a cobrar }\end{array}$} & A largo plazo & $\begin{array}{l}\text { Valores actuales de los importes a recibir, determinados utilizando los tipos de } \\
\text { interés vigentes apropiados, menos las correcciones por incobrabilidad y los } \\
\text { costes de cobranza, en su caso }\end{array}$ \\
\hline & A corto plazo & $\begin{array}{l}\text { El descuento no es obligatorio para las cuentas a cobrar a corto plazo cuando la } \\
\text { diferencia entre los importes nominales y descontados carezca de importancia } \\
\text { relativa }\end{array}$ \\
\hline \multirow{2}{*}{$\begin{array}{c}\text { Cuentas } \\
\text { a pagar, } \\
\text { deudas a } \\
\text { largo plazo } \\
\text { e ingresos } \\
\text { anticipados }\end{array}$} & A largo plazo & $\begin{array}{l}\text { La entidad adquirente utilizará los valores actuales de los desembolsos a realizar } \\
\text { para liquidar dichos pasivos, determinados según los tipos de interés vigentes } \\
\text { apropiados }\end{array}$ \\
\hline & A corto plazo & $\begin{array}{l}\text { El descuento no es obligatorio para los pasivos a corto plazo, cuando la diferencia } \\
\text { entre los importes nominales y descontados carezca de importancia relativa }\end{array}$ \\
\hline \multicolumn{2}{|l|}{$\begin{array}{l}\text { Pasivos } \\
\text { contingentes }\end{array}$} & $\begin{array}{l}\text { La adquirente utilizará los importes que hubiera cargado un tercero para asumir } \\
\text { tales pasivos contingentes. Este importe reflejará las expectativas sobre los } \\
\text { flujos de efectivo posibles, pero no la cantidad más probable ni el flujo de } \\
\text { efectivo máximo o mínimo esperado. } \\
\mathrm{Si} \text {, tras el reconocimiento inicial, el pasivo contingente se convierte en pasivo, y } \\
\text { la provisión necesaria es mayor que el valor razonable reconocido tras la } \\
\text { adquisición, el pasivo se incrementará. El importe adicional se reconocerá como } \\
\text { un gasto del ejercicio corriente (es decir, en el resultado del ejercicio). Si, tras el } \\
\text { reconocimiento inicial, la provisión reconocida fuera menor que el importe } \\
\text { reconocido en la adquisición, entonces el pasivo se reconocería a su valor razonable } \\
\text { en la adquisición y se disminuiría sólo si fuese adecuada una amortización o } \\
\text { nueva valoración en función de las normas de reconocimiento de los ingresos } \\
\text { ordinarios }\end{array}$ \\
\hline
\end{tabular}


4.5. Determinación del importe del fondo de comercio o de la diferencia negativa

En la fecha de adquisición se ha de comparar el coste de la combinación de negocios con el valor razonable de los activos, pasivos y pasivos identificables de la entidad adquirida para determinar la diferencia de la combinación. Si la diferencia es positiva, es decir, si el coste supera el valor razonable atribuido a los elementos adquiridos, se contabiliza un fondo de comercio que se lleva al activo del balance de la entidad adquirente dentro del inmovilizado intangible. Si la diferencia es negativa, es decir, cuando el valor razonable atribuido a los activos netos adquiridos supera al coste de la combinación, surge una diferencia negativa que se lleva inmediatamente a la cuenta de resultados como un ingreso.

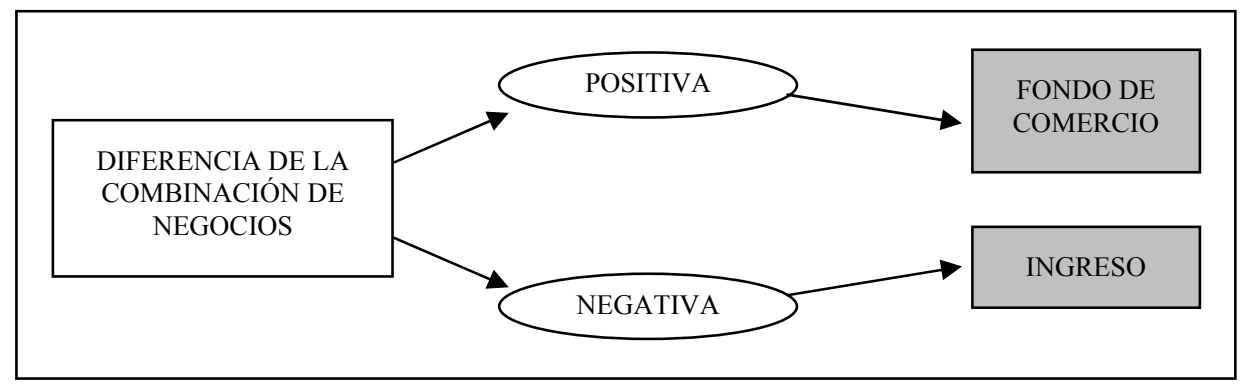

\subsubsection{El fondo de comercio}

El fondo de comercio representa el exceso, en la fecha de adquisición, del coste de la combinación de negocios sobre el correspondiente valor de los activos identificables adquiridos menos el de los pasivos asumidos (incluidos los pasivos contingentes).

La entidad adquirente reconocerá como un activo en la fecha de adquisición el fondo de comercio adquirido en la combinación de negocios; y valorará inicialmente ese fondo de comercio por su coste, siendo éste el exceso del coste de la combinación de negocios sobre la participación de la adquirente en el valor razonable neto de los activos, pasivos y pasivos contingentes identificables que haya reconocido. Representa un pago realizado por la adquirente como anticipo de beneficios económicos futuros de los activos que no hayan podido ser identificados individualmente y reconocidos por separado (párrafo 52, NIIF 3). Esta circunstancia puede deberse a los siguientes factores: 
- La valoración en el precio de compra de la capacidad futura de generar beneficios por parte de la sociedad adquirida. Esta superior capacidad de obtener beneficios se produce por la existencia de un conjunto de elementos intangibles, tales como clientela, situación geográfica, calidad del equipo humano, organización, etc., que individualmente considerados no cumplen las condiciones para tratarlos como activos en los estados financieros, pero por los cuales la entidad adquirente ha estado dispuesta a pagar en el momento de la adquisición. De ahí, que sea calificado como un fondo de comercio y reconocido como un activo De acuerdo con principios de contabilidad generalmente aceptados, el fondo de comercio sólo puede ser registrado contablemente cuando surge en virtud de una transacción, razón por la que la sociedad adquirida, aun habiéndolo generado, no lo ha incorporado a su activo. Sin embargo, en una combinación de negocios si ha de reflejarse, pues realmente, mediante la misma, lo que se está comprando es un negocio en marcha y dicho fondo de comercio representa un pago efectuado por la empresa adquirente anticipándose a los beneficios económicos futuros.

- Las expectativas que tiene la sociedad dominante basadas en la creencia de que con la incorporación de la sociedad adquirida a su área de influencia se obtendrán sinergias que proporcionarán al grupo mejores resultados que los que podría obtener cada empresa por separado. El sobreprecio pagado se convierte así, en una especie de prima satisfecha por la adquisición del control sobre el negocio o negocios adquiridos.

Dada la dificultad de identificar y distinguir estos dos componentes, u otros que puedan influir en la fijación del precio de compra, se tratan conjuntamente como un fondo de comercio, que debe ser contabilizado por su coste, menos la pérdida acumulada por deterioro de valor.

Como ya hemos apuntado, solamente podrá figurar en el activo, cuando su valor se ponga de manifiesto en virtud de una adquisición onerosa, en el contexto de una combinación de negocios. El fondo de comercio deberá asignarse desde la fecha de adquisición entre cada una de las unidades generadoras de efectivo o grupos de unidades generadoras de efectivo de la empresa, sobre los que se espere que recaigan los beneficios de las sinergias de la combinación de negocios. 
Tras el reconocimiento inicial, la adquirente valorará el fondo de comercio por su coste menos las pérdidas por deterioro imputables al mismo.

El fondo de comercio, por tanto, no se amortizará. En su lugar, las unidades generadoras de efectivo o grupos de unidades generadoras de efectivo a las que se haya asignado el fondo de comercio, se someterán, al menos anualmente ${ }^{4}$, a la comprobación del deterioro del valor, procediéndose, en su caso, al registro de la corrección valorativa por deterioro.

Las correcciones valorativas por deterioro reconocidas en el fondo de comercio no serán objeto de reversión en los ejercicios posteriores.

El artículo 213 del Texto Refundido de la Ley de Sociedades Anónimas relativo a la aplicación del resultado de la empresa, en la modificación introducida por la Ley $16 / 2007$, de 4 de julio, de reforma y adaptación de la legislación mercantil en materia contable para su armonización internacional con base en la normativa de la unión europea, establece la obligación de dotar una reserva indisponible equivalente al fondo de comercio que aparezca en el activo del balance, destinándose a tal efecto una cifra del beneficio que represente, al menos, un cinco por ciento del importe del citado fondo de comercio. Si no existiera beneficio, o éste fuera insuficiente, se emplearán reservas de libre disposición.

\subsubsection{La diferencia negativa}

En el supuesto excepcional de que el valor de los activos identificables adquiridos menos el de los pasivos asumidos, fuese superior al coste de la combinación de negocios, el exceso se contabilizará en la cuenta de pérdidas y ganancias como un ingreso.

Una buena muestra del carácter excepcional de estas situaciones se pone de manifiesto en la NIIF 3 (párrafo 56) donde se dispone que cuando el valor razonable de los activos, pasivos y pasivos contingentes identificables de la entidad adquirida comprados por la entidad adquirente, exceda al coste de la combinación de negocios, la entidad adquirente

$4 \quad$ O con una mayor frecuencia si se detectan indicios de deterioro. 
deberá en primer lugar comprobar la identificación y valoración de los activos identificables, pasivos y pasivos contingentes de la entidad adquirida, y la valoración del coste de la combinación de negocios, reconociendo solamente una diferencia negativa en la cuenta de pérdidas y ganancias, cuando persista la diferencia una vez realizada la comprobación anterior. Se está considerando, en definitiva, que la aparición de una diferencia negativa se limitará a aquellas situaciones en las que se hayan producido errores en la valoración de los elementos de la adquirida o en el coste de la combinación, o bien que la combinación de negocios se haya producido en términos muy ventajosos para la entidad adquirente; de ahí que se trate como un auténtico beneficio para esta entidad.

\section{Ejemplo $n^{0}$ 5.- Contabilización de una combinación de negocios}

En diciembre de XO las sociedades MARTINSA Y FADESA acuerdan llevar a cabo una combinación de negocios en virtud de la cual la sociedad MARTINSA absorberá a la sociedad FADESA.

La relación de canje de las acciones se establece en la proporción de una acción de MARTINSA por cada dos acciones de FADESA más $2 €$ por acción en efectivo. La fecha fijada para la realización de la fusión es el 1 de enero de X1.

El capital social de FADESA está formado por 200.000 acciones en circulación. El valor nominal de las acciones de MARTINSA es 5€, y su cotización el 1-1-X1 es de 6€ por acción.

La fusión ha supuesto los siguientes gastos: 9.000€ en asesoramiento legal, 3.000€ en notarios, registros y tasación y $2.500 €$ por la emisión de las nuevas acciones.

Los balances de las sociedades MARTINSA y FADESA a 1-1-X1 son los siguientes:

\begin{tabular}{|l|c|c|}
\hline & MARTINSA & FADESA \\
\hline Activo & 1.300 .000 & 700.000 \\
\hline Patrimonio neto & 700.000 & 500.000 \\
\hline Deudas & 500.000 & 200.000 \\
\hline
\end{tabular}

Los activos identificables de la sociedad FADESA tienen un valor razonable que asciende a 850.000€, mientras que el valor razonable de sus pasivos identificables coincide con su valor en libros. No hay activos intangibles ni pasivos contingentes en el negocio adquirido.

Se pide: Contabilizar la combinación de negocios de acuerdo con lo establecido en el PGC (prescindiendo de consideraciones fiscales).

\section{Solución.-}

Dado que el 1-1-X1 la sociedad MARTINSA absorbe a la sociedad FADESA se produce una combinación de negocios en virtud de la cual la primera entidad adquiere el control de la segunda. Con arreglo a lo dispuesto en la norma de registro y valoración $\mathrm{n}^{\mathrm{o}} 19$ esta combinación se ha de contabilizar por el método de adquisición. 


\section{IDENTIFICACIÓN DE LA ENTIDAD ADQUIRENTE}

En este ejemplo no existen dificultades para identificar cuál de las entidades participantes adquiere el control de otra entidad, ya que la sociedad MATINSA emite las acciones y paga una cantidad en metálico por la compra; además, el tamaño de MARTINSA también es significativamente más alto que el de la sociedad FADESA. Por tanto, todos los indicios nos llevan a considerar a la sociedad MARTINSA como la empresa adquirente.

\section{FECHA DE ADQUISICIÓN}

Como la entrega de las acciones emitidas por MARTINSA a los socios de FADESA se efectúa el 1-1-X1, recibiendo a cambio el patrimonio de FADESA, dicha fecha será considerada como la fecha de adquisición a efectos de aplicar el método de adquisición a la combinación de negocios.

\section{COSTE DE LA COMBINACIÓN DE NEGOCIOS}

- Valor razonable de los activos entregados (efectivo) $=2 € /$ acción de FADESA $\times$ 100.000 acciones $=200.000 €$.

- Valor razonable de los instrumentos de capital emitidos $(1-1-\mathrm{X} 5)=100.000$ acciones $\times 6 € /$ acción $=600.000 €$

- (Número de acciones emitidas por $\mathrm{A}=200.000 / 2=100.000$ acciones)

- Costes directamente atribuibles:

\begin{tabular}{|c|c|}
\hline Gastos de asesoramiento legal & 9.000 \\
\hline 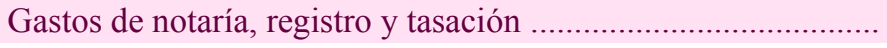 & 3.000 \\
\hline STES DIRECTAMENTE ATRIBUIBLES & 12.000 \\
\hline
\end{tabular}

Los gastos de emisión de los instrumentos de patrimonio (2.500€) no se consideran costes directamente atribuibles a la combinación de negocios tratándose conforme a lo que el PGC establece en la norma relativa a los instrumentos financieros, es decir como un menor importe del efectivo conseguido.

El coste total de la combinación de negocios ascenderá, por lo tanto, a:

\begin{tabular}{lr} 
Valor razonable de los activos entregados ................................ & 200.000 \\
Valor razonable instrumentos de capital emitidos $\ldots \ldots \ldots \ldots \ldots \ldots \ldots .$. & 600.000 \\
Costes directamente atribuibles a la combinación $\ldots \ldots \ldots \ldots \ldots \ldots \ldots .$. & 12.000 \\
\hline COSTE DE LA COMBINACIÓN ............................................................. & 812.000
\end{tabular}

\section{VALORACIÓN DE LOS ACTIVOS, PASIVOS Y PASIVOS CONTINGENTES DE LA ENTIDAD ADQUIRIDA}

Valor razonable neto de la entidad adquirida:

Porcentaje comprado $=100 \%$

Valor razonable de activos adquiridos

Valor razonable de pasivos asumidos

Valor razonable del patrimonio neto de la sociedad FADESA . 650.000 
La valoración de los activos y pasivos identificables de la entidad adquirente no se modifican como consecuencia de la combinación de negocios.

Hay que hacer notar que la incorporación de los activos netos identificables de la entidad FADESA por su valor razonable puede originar un pasivo o activo por impuesto diferido en la medida en que dicho valor razonable no coincida con su base fiscal, cuestión que abordaremos más adelante.

\section{CÁlCULO DEL FONDO DE COMERCIO O DE LA DIFERENCIA NEGATIVA DE LA COMBINACIÓN}

Diferencia de la combinación:

\begin{tabular}{|c|c|}
\hline $\begin{array}{l}\text { Coste de la combinación } \\
\text { VR neto de B adquirido }\end{array}$ & $\begin{array}{r}812.000 \\
(650.000)\end{array}$ \\
\hline Diferencia positiva & 162.000 \\
\hline
\end{tabular}

Esta diferencia positiva será considerada un fondo de comercio dado que surge como consecuencia de la compra de un negocio. Se incluirá dentro del inmovilizado intangible de la entidad MARTINSA y no se amortizará, sino que será sometido a un test de deterioro con carácter anual o con mayor frecuencia en caso de que se aprecien indicios de deterioro.

\section{CONTABILIZACIÓN DE LA COMBINACIÓN DE NEGOCIOS EN LA ENTIDAD ADQUIRENTE MARTINSA}

Apuntes contables por los instrumentos de capital emitidos, gastos de emisión, de asesoramiento legal, de revisión contable, y registros y notaría:

Emisión de los instrumentos de capital:

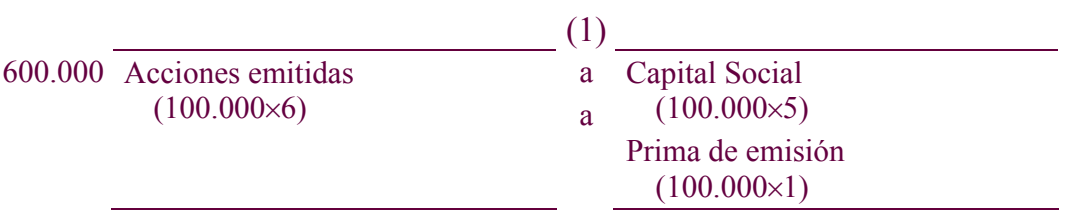

Por los gastos de emisión de las acciones:

$$
2.500 \text { Primas de emisión }
$$

Apunte contable por la recepción de activos y pasivos de la entidad FADESA, por la entrega de las acciones a lo socios de FADESA y la salida de la tesorería para hacer frente al pago en efectivo y a los costes directamente imputables a la combinación de negocios.

\subsection{Activos \\ 162.000 Fondo de comercio}

(3)

Acciones emitidas $\quad 600.000$

a Tesorería 
Ejemplo $n^{0}$ 6.- Combinación de negocios mediante la formación de un grupo de sociedades

La entidad AGASA adquirió el 31-12-X0 mediante una oferta pública de adquisición de acciones el $60 \%$ de los instrumentos de capital con derecho a voto de la entidad FILESA pagando 150.000€. AGASA ha incurrido, además, en unos costes de tasación de 5.000€.

A 31-12-X0, los balances individuales homogeneizados de las entidades AGASA Y FILESA son los siguientes:

\begin{tabular}{|l|c|c|}
\hline Activo & AGASA & FILESA \\
\hline Terrenos & 40.000 & 30.000 \\
\hline Construcciones (netas) & 60.000 & 60.000 \\
\hline Participación en entidad FILESA & 155.000 & ---- \\
\hline Existencias & 50.000 & 70.000 \\
\hline Deudores & 55.000 & 50.000 \\
\hline Tesorería & 30.000 & 20.000 \\
\hline TOTAL $\boldsymbol{A C T I V O}$ & $\mathbf{3 9 0 . 0 0 0}$ & $\mathbf{2 3 0 . 0 0 0}$ \\
\hline
\end{tabular}

\begin{tabular}{|l|c|c|}
\hline Pasivo & AGASA & FILESA \\
\hline Capital social & 60.000 & 20.000 \\
\hline Reservas & 100.000 & 100.000 \\
\hline Resultado del ejercicio & 50.000 & 40.000 \\
\hline Acreedores a largo plazo & 120.000 & 40.000 \\
\hline Acreedores a corto plazo & 60.000 & 30.000 \\
\hline TOTAL PASIVO & $\mathbf{3 9 0 . 0 0 0}$ & $\mathbf{2 3 0 . 0 0 0}$ \\
\hline
\end{tabular}

En la fecha de adquisición de la participación se pusieron de manifiesto los siguientes hechos respecto a la valoración a su valor razonable de los activos y pasivos identificables de la sociedad FILESA:

- Como consecuencia de una plusvalía latente en los terrenos de FILESA, su valor razonable asciende a $40.000 €$.

- El valor razonable de las existencias, establecido mediante su coste corriente de reposición, se estima en $85.000 €$.

- Las construcciones (netas) de FILESA presentan un valor de mercado de 80.000€ con una vida útil restante de 10 años.

- FILESA ha desarrollado una base de datos que no tiene reconocida en balance. AGASA considera que cumple los requisitos para reconocerse como activo intangible estableciendo un valor razonable por referencia a un mercado activo de $8.500 €$.

- En la fecha de la adquisición de la participación se tiene conocimiento de una demanda por incumplimiento de una garantía postventa interpuesta contra FILESA por un cliente. Se está ultimando un acuerdo extrajudicial con el cliente que aceptaría recibir una indemnización a cambio de la retirada de la demanda. El valor actual de la indemnización, que se hará efectiva en junio del año X1, puede establecerse fiablemente en $4.000 €$.

Se pide: Contabilización de la inversión en la empresa del grupo en las cuentas individuales de AGASA y elaboración de las cuentas consolidadas del grupo AGASA / FILESA en la fecha de adquisición (Prescíndase de consideraciones fiscales). 


\section{Solución.-}

La compra por AGASA del $60 \%$ del capital con derecho a voto de FILESA mediante una OPA es una combinación de negocios en virtud de la cual la primera entidad adquiere la posibilidad de controlar a la segunda formando un grupo de sociedades. AGASA como entidad dominante tiene la obligación de elaborar cuentas consolidadas aplicando el método de integración global.

\section{CONTABILIDAD DE LA PARTICIPACIÓN EN LA EMPRESA DEL GRUPO EN LAS CUENTAS INDIVIDUALES DE AGASA}

De acuerdo con la norma de registro y valoración $\mathrm{n}^{\circ}$ 9, apartado 2.5.1 del PGC, la valoración inicial de una inversión en empresas del grupo se debe realizar al coste, que equivaldrá al valor razonable de la contraprestación entregada más los gastos de transacción que les sean directamente atribuibles. En este caso a la cantidad pagada por las acciones hay que sumarle los gastos de la tasación dado que son ocasionados directamente por la combinación de negocios:

+ Valor razonable de la contraprestación entregada .....................
+ Gastos de la transacción que le son directamente imputables .....

El asiento que habrá realizado la entidad AGASA en sus cuentas individuales a 31-12-X0 será tal y como se deduce de su balance:
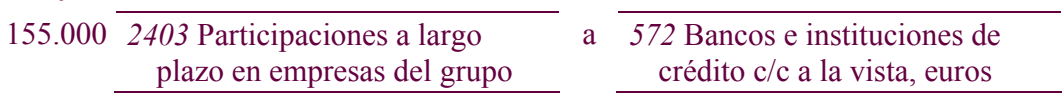

Posteriormente, las inversiones en el patrimonio de empresas del grupo se valorarán por su coste, menos, en su caso, el importe acumulado de las correcciones valorativas por deterioro, que deberán efectuarse al menos al cierre del ejercicio, siempre que exista evidencia objetiva de que el valor en libros de una inversión no será recuperable.

\section{ELABORACIÓN DE LAS CUENTAS CONSOLIDADAS DEL GRUPO AGASA/FILESA A 31-12-X0}

La sociedad AGASA es la entidad adquirente en esta combinación de negocios dado que es la que adquiere el control y ha de elaborar las cuentas consolidadas mediante la aplicación del método de integración global, pues de acuerdo con el art. 42 del Código de Comercio, en la redacción dada por la Ley de Reforma de la Legislación Mercantil, de 4 de julio de 2007, toda sociedad dominante de un grupo de sociedades estará obligada a formular las cuentas anuales y el informe de gestión consolidados.

La fecha de la consolidación será la fecha de adquisición de la participación, es decir, el 31-12-X0.

Establecimiento del valor razonable de los activos, pasivos y pasivos contingentes identificables de la entidad adquirida FILESA al 31-12-X0:

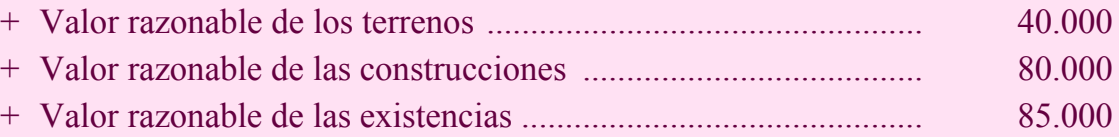


+ Valor razonable de los deudores

+ Valor razonable de la tesorería

+ Valor razonable del inmovilizado intangible puesto de manifiesto en la combinación de negocios

- Valor razonable de los acreedores a largo plazo

- Valor razonable de los acreedores a corto plazo

- Valor razonable de la provisión para otras responsabilidades puesta de manifiesto en el momento de la combinación de negocios

= Valor razonable de los activos netos de FILESA

Como se observa, en este caso, se incluyen dentro de los activos y pasivos identificables de la entidad dependiente el activo intangible que cumple con los criterios de reconocimiento del PGC y la provisión para otras responsabilidades que ocasionará un pago futuro probable y cuyo valor puede establecerse con fiabilidad, independientemente de que dichas partidas no estuviesen previamente contabilizadas en las cuentas individuales de la sociedad FILESA.

Determinación de la diferencia de la combinación de negocios:

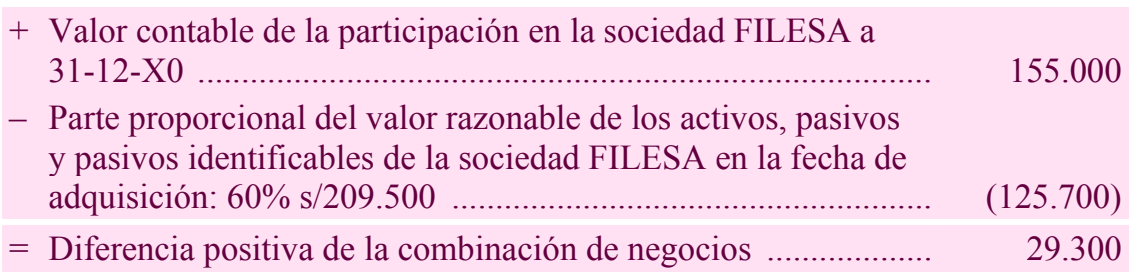

La diferencia positiva que subsista después de la compensación realizada se inscribirá en el balance consolidado en una partida especial, con denominación adecuada, como un fondo de comercio de consolidación.

Cálculo de los intereses minoritarios en la sociedad FILESA:

A los intereses minoritarios les corresponde el 40\% del valor razonable de los activos, pasivos y pasivos contingentes identificables de la entidad FILESA:

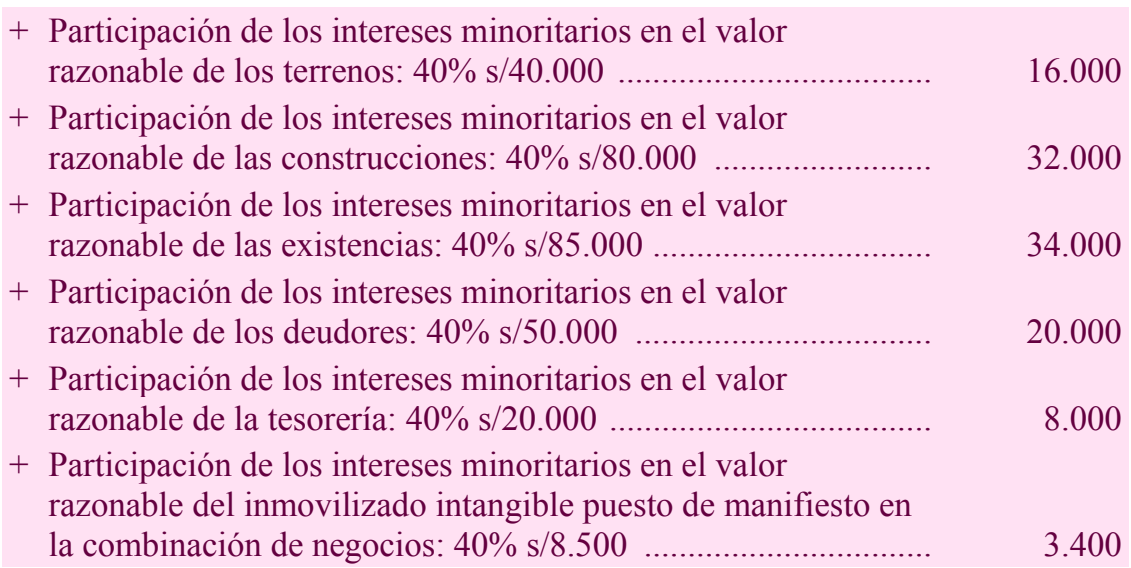


Participación de los intereses minoritarios en el valor razonable de los acreedores a largo plazo: $40 \% \mathrm{~s} / 40.000$

- Participación de los intereses minoritarios en el valor razonable de los acreedores a corto plazo: $40 \% \mathrm{~s} / 30.000$

- Participación de los intereses minoritarios en el valor razonable de la provisión para riesgos puesta de manifiesto en el momento de la combinación de negocios: $40 \% \mathrm{~s} / 4.000$

$=$ Participación de los intereses minoritarios en los activos netos de FILESA

Asiento de eliminación inversión - patrimonio neto:

(1)

$\begin{aligned} & 20.000 \text { Capital social (FILESA) } \\ & 100.000 \text { Reservas (FILESA) } \\ & 40.000 \text { Resultados del ejercicio (FILESA) } \\ & 10.000 \text { Terrenos (FILESA) } \\ & 8.500 \text { Aplicaciones informáticas } \\ & \text { (FILESA) } \\ & 20.000 \text { Construcciones netas (FILESA) } \\ & 15.000 \text { Existencias (FILESA) } \\ & 29.300 \text { Fondo de comercio de } \\ & \text { consolidación } \\ &\end{aligned}$

a Participación en FILESA (AGASA)

155.000

a Provisión para otras responsabilidades $\quad 4.000$

a Intereses minoritarios $\quad 83.800$

Balance consolidado del grupo AGASA - FILESA al 31-12-X0:

\begin{tabular}{|l|r|l|r|}
\hline Activo & Importes & Pasivo & Importes \\
\hline Aplicaciones informáticas & 8.500 & Capital social & 60.000 \\
\hline Fondo de comercio & 29.300 & Reservas & 100.000 \\
\hline Terrenos & 80.000 & Resultado del ejercicio & 50.000 \\
\hline Construcciones (netas) & 140.000 & Intereses minoritarios & 83.800 \\
\hline Existencias & 135.000 & Provisión para otras responsabilidades & 4.000 \\
\hline Deudores & 105.000 & Acreedores a largo plazo & 160.000 \\
\hline Tesorería & 50.000 & Acreedores a corto plazo & 90.000 \\
\hline TOTAL ACTIVO & $\mathbf{5 4 7 . 8 0 0}$ & TOTAL ACTIVO & $\mathbf{5 4 7 . 8 0 0}$ \\
\hline
\end{tabular}

Hoja de trabajo para la elaboración del balance consolidado: 


\begin{tabular}{|c|c|c|c|c|c|c|c|c|c|c|c|c|c|c|c|c|c|}
\hline \multirow{2}{*}{ 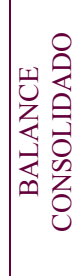 } & 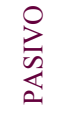 & & & & & & & $\begin{array}{l}\text { ¿े } \\
\text { : }\end{array}$ & \& & $\begin{array}{l}8 \\
\stackrel{0}{0} \\
\text { in }\end{array}$ & $\begin{array}{l}8 \\
8 \\
0 \\
0\end{array}$ & $\begin{array}{l}\stackrel{8}{\circ} \\
\stackrel{\leftrightarrow}{ }\end{array}$ & & 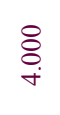 & & $\begin{array}{l}8 \\
\infty \\
\infty \\
\infty\end{array}$ & $\begin{array}{l}\stackrel{8}{ } \\
\infty \\
\stackrel{+}{n} \\
\text { in }\end{array}$ \\
\hline & 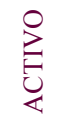 & $\begin{array}{l}\stackrel{8}{0} \\
\stackrel{\infty}{0}\end{array}$ & $\begin{array}{l}8 \\
\stackrel{0}{+} \\
\dot{+}\end{array}$ & & $\begin{array}{l}8 \\
\stackrel{0}{0} \\
\stackrel{m}{2}\end{array}$ & $\begin{array}{l}8 \\
\vdots \\
0 \\
0\end{array}$ & $\begin{array}{l}8 \\
\vdots \\
\dot{0}\end{array}$ & & & & & & 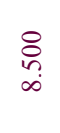 & & $\begin{array}{l}\text { \&े } \\
\text { ते } \\
\text { ते }\end{array}$ & & $\begin{array}{l}8 \\
\infty \\
\infty \\
\stackrel{+}{+} \\
\text { n. }\end{array}$ \\
\hline \multirow{2}{*}{ 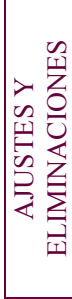 } & 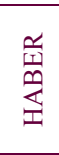 & & & $\begin{array}{l}\widehat{\Xi} \\
\vdots \\
\vdots \\
\dot{b} \\
b\end{array}$ & & & & & & & & & & $\begin{array}{l}\hat{\Xi} \\
\stackrel{8}{0} \\
\dot{+}\end{array}$ & & $\begin{array}{l}\widehat{\Xi} \\
8 \\
\infty \\
\infty \\
\infty\end{array}$ & $\begin{array}{l}\text { \& } \\
\infty \\
\stackrel{J}{J} \\
\text { J }\end{array}$ \\
\hline & 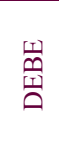 & $\begin{array}{l}\widehat{\Xi} \\
8 \\
\circ \\
0\end{array}$ & $\begin{array}{l}\widehat{\Xi} \\
\stackrel{8}{0} \\
\stackrel{0}{0}\end{array}$ & & $\begin{array}{l}\widehat{\Xi} \\
8 \\
8 \\
\text { in }\end{array}$ & & & $\begin{array}{l}\widehat{\Xi} \\
8 \\
8 \\
\stackrel{i}{0}\end{array}$ & $\begin{array}{l}0 \\
8 \\
8 \\
\dot{8}\end{array}$ & $\begin{array}{l}\widehat{\Xi} \\
\stackrel{8}{\circ} \\
\stackrel{+}{+}\end{array}$ & & & 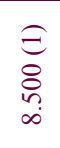 & & $\begin{array}{l}\widehat{\Xi} \\
\stackrel{0}{0} \\
0 \\
\text { ते }\end{array}$ & & 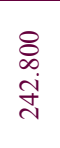 \\
\hline \multirow[t]{2}{*}{ 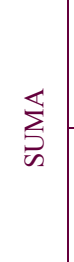 } & 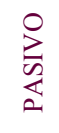 & & & & & & & $\begin{array}{l}\stackrel{8}{0} \\
\dot{\infty}\end{array}$ & \&̊ & $\begin{array}{l}\stackrel{\circ}{0} \\
\stackrel{\leftrightarrow}{\circ}\end{array}$ & $\begin{array}{l}8 \\
\stackrel{0}{0} \\
\stackrel{0}{0}\end{array}$ & $\begin{array}{l}8 \\
\stackrel{0}{0} \\
\text { o. }\end{array}$ & & & & & $\begin{array}{l}\stackrel{0}{0} \\
\stackrel{్}{0}\end{array}$ \\
\hline & 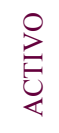 & $\begin{array}{l}\stackrel{8}{\circ} \\
\stackrel{1}{\circ}\end{array}$ & $\begin{array}{l}8 \\
\stackrel{0}{0} \\
\stackrel{\Xi}{1}\end{array}$ & $\begin{array}{l}8 \\
\vdots \\
\text { in } \\
n\end{array}$ & 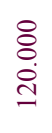 & $\begin{array}{l}8 \\
\vdots \\
\dot{0} \\
\varrho\end{array}$ & $\begin{array}{l}\text { ¿े } \\
\stackrel{\circ}{\circ}\end{array}$ & & & & & & & & & & $\begin{array}{l}\& \\
\stackrel{\leftrightarrow}{0} \\
\text {. }\end{array}$ \\
\hline \multirow{2}{*}{ 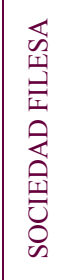 } & $\sum_{\substack{0 \\
\vdots \\
\vdots}}^{0}$ & & & & & & & $\begin{array}{l}\text { ¿े } \\
\stackrel{\sim}{+}\end{array}$ & $\begin{array}{l}8 \\
\stackrel{0}{\circ} \\
\end{array}$ & $\begin{array}{l}\stackrel{8}{0} \\
\dot{+} \\
\dot{q}\end{array}$ & $\begin{array}{l}\stackrel{\Xi}{0} \\
\dot{+}\end{array}$ & 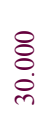 & & & & & $\begin{array}{l}\stackrel{8}{0} \\
\stackrel{0}{0} \\
\text { त. }\end{array}$ \\
\hline & 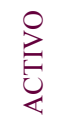 & @ి & ¿े. & & $\begin{array}{l}\stackrel{8}{0} \\
\stackrel{0}{1}\end{array}$ & 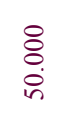 & 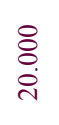 & & & & & & & & & & $\begin{array}{l}\stackrel{0}{0} \\
\stackrel{\oplus}{0} \\
\text {. }\end{array}$ \\
\hline \multirow{2}{*}{ 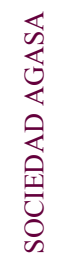 } & 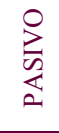 & & & & & & & $\begin{array}{l}8 \\
8 \\
\\
0\end{array}$ & $\begin{array}{l}8 \\
\dot{0} \\
\stackrel{0}{0}\end{array}$ & $\begin{array}{l}\text { ̊े } \\
\stackrel{\circ}{\circ}\end{array}$ & $\begin{array}{l}\stackrel{8}{0} \\
\stackrel{+}{1}\end{array}$ & $\begin{array}{l}8 \\
8 \\
0 \\
0\end{array}$ & & & & & $\begin{array}{l}\stackrel{8}{0} \\
\stackrel{\circ}{\circ} \\
\text { مे }\end{array}$ \\
\hline & 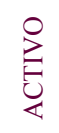 & $\begin{array}{l}\stackrel{8}{0} \\
\dot{+}\end{array}$ & $\begin{array}{l}8 \\
8 \\
8 \\
8\end{array}$ & $\begin{array}{l}8 \\
\vdots \\
\ddot{n} \\
n\end{array}$ & $\begin{array}{l}\text { \&̊ } \\
\text { ¿. }\end{array}$ & $\begin{array}{l}8 \\
\text { in } \\
\text { in }\end{array}$ & ¿े. & & & & & & & & & & $\begin{array}{l}\stackrel{8}{0} \\
\stackrel{+}{\circ} \\
\text { }\end{array}$ \\
\hline \multicolumn{2}{|c|}{ 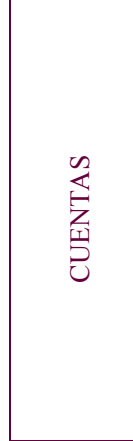 } & $\begin{array}{l}\stackrel{0}{0} \\
\stackrel{\Xi}{\Xi}\end{array}$ & 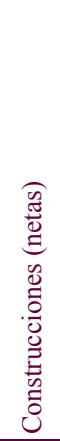 & 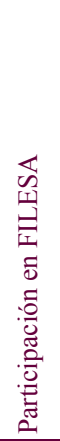 & 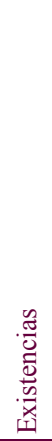 & $\begin{array}{l}\text { o. } \\
0 \\
0 \\
\overline{0} \\
0\end{array}$ & 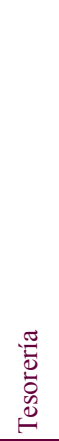 & 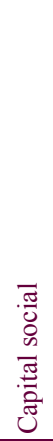 & 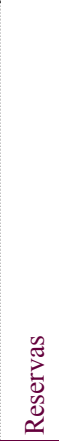 & 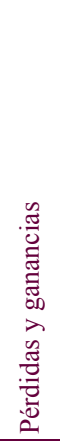 & 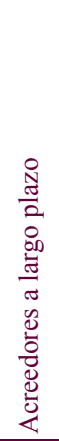 & 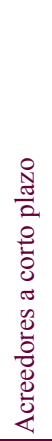 & 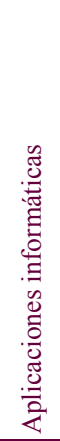 & 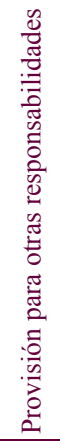 & 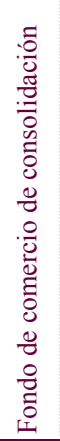 & 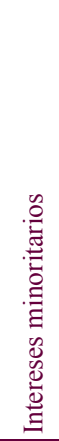 & 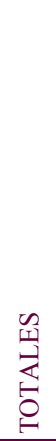 \\
\hline
\end{tabular}


Si suponemos ahora que el precio de compra de la participación ascendió $115.000 €$ más los gastos de tasación, la participación en la empresa del grupo estará contabilizada en el activo del balance de AGASA por $120.000 €$.

En esta hipótesis la diferencia de la combinación sería:

+ Valor contable de la participación en la sociedad FILESA a 31-12-X0

- Parte proporcional del valor razonable de los activos, pasivos y pasivos identificables de la sociedad FILESA en la fecha de adquisición: $60 \% \mathrm{~s} / 209.500$

$=$ Diferencia negativa de la combinación de negocios

En este caso, que el PGC considera con carácter excepcional, la diferencia negativa se lleva directamente a la cuenta de resultados del ejercicio como un ingreso, siendo en este caso el asiento de eliminación inversión - patrimonio neto el siguiente:

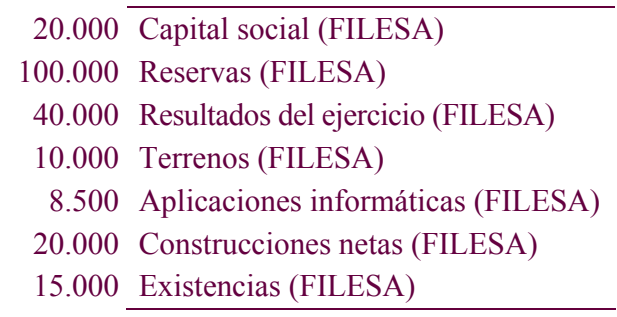

(1)

a Participación en FILESA (AGASA) 120.000

a Provisión para otras responsabilidades $\quad 4.000$

a Resultado del ejercicio $\quad 5.700$

a Intereses minoritarios $\quad 83.800$

Además, hay que precisar que según la norma de registro y valoración $\mathrm{n}^{\circ} 19$, apartado 2.4.5, del PGC en ningún caso se registrarán los inmovilizados intangibles identificados cuya valoración no pueda ser calculada por referencia a un mercado activo, si ello originase la contabilización de un ingreso en la cuenta de pérdidas y ganancias, como consecuencia de una diferencia negativa de consolidación. Por tanto, si el valor razonable de la aplicación informática no se hubiese podido realizar por referencia a un mercado activo, tal elemento no se podría reflejar contablemente, en tanto en cuanto existiese dicha diferencia negativa.

\section{Ejemplo $\mathbf{n}^{0}$ 7.- Análisis del deterioro del fondo de comercio}

El 31-12-X1 la sociedad TENCA adquiere por 350.000€ una división completa de la sociedad CARPA. Esta división se dedica a la fabricación y venta de un producto concreto que la sociedad TENCA utiliza como materia prima.

El valor razonable de los activos identificables del negocio adquirido es de 600.000€ y el de los pasivos asumidos es de 400.000€. La sociedad TENCA considera que el negocio adquirido constituye en su totalidad una única unidad generadora de efectivo.

Los inmovilizados incluidos en la unidad generadora de efectivo son amortizados a un ritmo de $70.000 €$ anuales. 
A 31-12-X4 la sociedad TENCA observa indicios de deterioro en el negocio adquirido a la entidad CARPA; El valor de uso del negocio adquirido estimado por la sociedad TENCA en esa fecha es de 350.000€. Por su parte, el valor razonable del negocio adquirido es de $370.000 €$ con unos gastos de venta de 5.000€.

Se pide: Contabilizar, en su caso, el deterioro del negocio adquirido.

\section{Solución.-}

Se trata de una combinación de negocios que ha de ser contabilizada por el método de adquisición.

La sociedad TENCA es la empresa adquirente pues es la que obtiene el control sobre el negocio adquirido, siendo la fecha de adquisición el 31-12-X1.

\section{CÁLCULO DE LA DIFERENCIA DE LA COMBINACIÓN DE NEGOCIOS}

+ Coste de la combinación de negocios en la fecha de adquisición

- Parte proporcional del valor razonable de los activos netos identificables adquiridos: (600.000-400.000)

$=$ Fondo de comercio

Fondo de comercio que se asigna a la unidad generadora de efectivo constituida por el negocio adquirido, dado que forma el grupo más pequeño de activos que genera entradas de efectivo por su funcionamiento continuado, que son en buena medida independientes de las entradas producidas por otros activos o grupos de activos.

\section{AMORTIZACIÓN ACUMULADA DE LOS ACTIVOS AMORTIZABLES DEL NEGOCIO ADQUIRIDO}

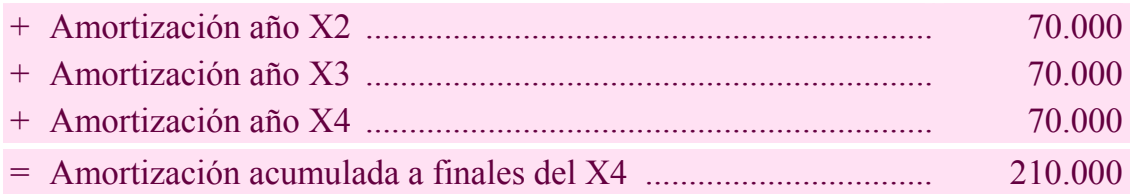

VALOR CONTABLE DE LOS ACTIVOS IDENTIFICABLES ADQUIRIDOS EN LA COMBINACIÓN DE NEGOCIOS

\begin{tabular}{|c|c|}
\hline 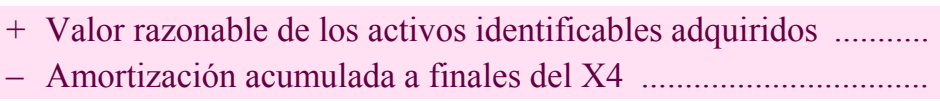 & $\begin{array}{r}600.000 \\
(210.000)\end{array}$ \\
\hline $\begin{array}{l}=\text { Valor neto contable de los activos identificables adquiridos a } \\
\text { finales del X4 }\end{array}$ & 00 \\
\hline
\end{tabular}

\section{VALOR EN LIBROS DEL FONDO DE COMERCIO A FINALES DEL X4 $=150.000$}

Una unidad generadora de efectivo, a la que se ha distribuidos fondo de comercio, se someterá a la comprobación del deterioro del valor anualmente, y también cuando existan indicios de que la unidad podría haberse deteriorado, comparando el importe en libros de la 
unidad, incluido el fondo de comercio, con el importe recuperable de la misma. Si el importe recuperable de la unidad excediese a su importe en libros, la unidad y el fondo de comercio atribuido a esa unidad se considerarán como no deteriorados. Si el importe en libros de la unidad excediese su importe recuperable, la entidad reconocerá la pérdida por deterioro del valor.

VALOR EN LIBROS DE LA UNIDAD GENERADORA DE EFECTIVO FORMADA POR EL NEGOCIO ADQUIRIDO

$\begin{array}{rlr}+ & \text { Valor neto contable de los activos identificables adquiridos a } \\ & \text { finales del X4 ..................................................................... } & 390.000 \\ + & \text { Fondo de comercio asignado a la unidad generadora de efectivo .. } & 150.000 \\ = & \text { Valor en libros de la unidad generadora de efectivo formada } \\ & \text { por el negocio adquirido a finales del X4 ................................ }\end{array}$

\section{IMPORTE RECUPERABLE DE LA UNIDAD GENERADORA DE EFECTIVO A FINALES DEL X9}

Será el mayor entre el valor de uso (350.000€) y el valor razonable menos los costes de venta (365.000€); en este caso el importe recuperable será de 365.000€.

\section{DETERIORO EXISTENTE EN LA UNIDAD GENERADORA DE EFECTIVO A FINALES DEL X9}

\begin{tabular}{|c|c|}
\hline $\begin{array}{l}+ \text { Valor en libros de la unidad generadora de efectivo formada } \\
\text { por el negocio adquirido a finales del X4 }\end{array}$ & 540.000 \\
\hline $\begin{array}{l}\text { - Importe recuperable de la unidad generadora de efectivo a } \\
\text { finales del X4 }(370.000-5.000)\end{array}$ & 36 \\
\hline$=$ Deterioro de la unidad generadora de efectivo & 175.000 \\
\hline
\end{tabular}

El PGC indica en su norma de valoración 2 que en caso de que la empresa deba reconocer una pérdida por deterioro de una unidad generadora de efectivo a la que se hubiese asignado todo o parte de un fondo de comercio, reducirá en primer lugar el valor contable del fondo de comercio correspondiente a dicha unidad. Si el deterioro superase el importe de éste, en segundo lugar, reducirá en proporción a su valor contable el del resto de activos de la unidad generadora de efectivo, hasta el límite del mayor valor entre los siguientes: su valor razonable menos los costes de venta, su valor en uso y cero

\section{APLICACIÓN DEL DETERIORO}

- Deterioro irreversible del fondo de comercio $=150.000 €$.

- Deterioro reversible de los activos identificables de la unidad generadora de efectivo $=25.000 €$.

Contabilización del deterioro:

\begin{tabular}{|c|c|}
\hline 150.000 & $\begin{array}{l}690 \text { Pérdidas por deterioro del } \\
\text { inmovilizado intangible }\end{array}$ \\
\hline 2 & $\begin{array}{l}691 \text { Pérdidas por deterioro del } \\
\text { inmovilizado material }\end{array}$ \\
\hline
\end{tabular}

(1)

a 204 Fondo de comercio
a 291 Deterioro de valor del
inmovilizado material

150.000 
Una pérdida por deterioro del valor reconocida en el fondo de comercio no revertirá en los ejercicios posteriores; de ahí que se abone directamente a la cuenta "204. Fondo de comercio". El PGC y la NIC 38 prohíben el reconocimiento de un fondo de comercio generado internamente. Cualquier incremento en el importe recuperable del fondo de comercio, en los ejercicios siguientes al reconocimiento de una pérdida por deterioro del valor, será probablemente un aumento del fondo de comercio generado internamente, y no una reversión de la pérdida por deterioro del valor reconocida para el fondo de comercio adquirido.

\section{EFECTO FISCAL DEL RECONOCIMIENTO DE LOS ACTIVOS NETOS DEL NEGOCIO ADQUIRIDO POR SU VALOR RAZONABLE}

La norma de registro y valoración $\mathrm{n}^{\circ} 13$ del PGC establece el tratamiento contable del impuesto sobre beneficios e incluye algunas disposiciones que afectan a las combinaciones de negocios; en particular, considera las diferencias temporarias como aquéllas derivadas de la diferente valoración, contable y fiscal, atribuida a los activos, pasivos y determinados instrumentos de patrimonio de la empresa, en la medida en que tengan incidencia en la carga fiscal futura. Por su parte, la valoración fiscal de un activo, pasivo o instrumento de patrimonio, denominada base fiscal, es el importe atribuido a dicho elemento de acuerdo con la legislación fiscal aplicable. En la medida en que la aplicación del método de adquisición en las combinaciones de negocios, exige valorar los activos y pasivos identificables adquiridos tomando como referencia sus valores razonables y que éstos pueden diferir de su base fiscal, pueden surgir diferencias temporarias. Las diferencias temporarias serán imponibles cuando den lugar a mayores cantidades a pagar o menores cantidades a devolver por impuestos en ejercicios futuros, originándose en el caso de activos cuando el valor contable es mayor que su base fiscal y en el caso de pasivos o de instrumentos de patrimonio cuando el valor contable es menor que su base fiscal. Las diferencias temporarias serán deducibles cuando den lugar a menores cantidades a pagar o a mayores cantidades a devolver por impuestos en ejercicios futuros, originándose en el caso de activos cuando el valor contable es menor que su base fiscal y en el caso de pasivos o de instrumentos de patrimonio cuando el valor contable es mayor que su base fiscal.

Si bien las diferencias temporarias se producen normalmente, por la existencia de diferencias temporales entre la base imponible y el resultado contable antes de impuestos, cuyo origen se encuentra en los 
diferentes criterios temporales de imputación empleados para determinar ambas magnitudes y que, por tanto, revierten en períodos subsiguientes, el PGC hace mención expresa de otras situaciones que también las producen entre las que hay que destacar por su relación con el tema que nos ocupa, las combinaciones de negocios, cuando los elementos patrimoniales se registran por un valor contable (concretamente el valor razonable) que difiere del valor atribuido a efectos fiscales.

En general, se reconocerá un pasivo por impuesto diferido por todas las diferencias temporarias imponibles, a menos que éstas hubiesen surgido del reconocimiento inicial de un fondo de comercio. Sin embargo, los pasivos por impuesto diferido relacionados con un fondo de comercio, se registrarán siempre que no hayan surgido de su reconocimiento inicial.

Ejemplo $n^{0}$ 8.- Efecto impositivo del reconocimiento inicial de una combinación de negocios

La sociedad GAMESA adquiere por 520.000€ en el marco de una combinación de negocios a la sociedad ENASA. En el momento de llevarse a cabo la combinación de negocios, 31-12-X0, la sociedad ENASA presentaba los siguientes valores contables y razonables para sus elementos patrimoniales:

\begin{tabular}{|l|c|c|}
\hline Elementos & Valor contable & Valor razonable \\
\hline Activos no corrientes. Terrenos & 280.000 & 360.000 \\
\hline Activos no corrientes. Edificios & 150.000 & 130.000 \\
\hline Otros activos no corrientes & 50.000 & 50.000 \\
\hline Activos corrientes & 230.000 & 230.000 \\
\hline TOTAL ACTIVO & 710.000 & 770.000 \\
\hline Patrimonio neto & 420.000 & 495.000 \\
\hline Pasivos no corrientes & 195.000 & 180.000 \\
\hline Pasivos corrientes & 30.000 & 20.000 \\
\hline TOTAL PASIVO & $\mathbf{7 4 0 . 0 0 0}$ & $\mathbf{7 7 0 . 0 0 0}$ \\
\hline
\end{tabular}

Los activos y pasivos de la sociedad ENASA se incorporan al balance de la sociedad GAMESA por sus valores razonables. El tipo impositivo es del $30 \%$.

Se pide: Determinar la diferencia de la combinación de negocios, así como los efectos impositivos asociados a las diferencias temporarias puestas de manifiesto en la combinación de negocios.

\section{Solución.-}

En primer lugar vamos a determinar las diferencias temporarias y sus correspondientes activos y pasivos por impuestos diferidos que han surgido como consecuencia de la combinación de negocios. 


\begin{tabular}{|l|c|c|c|c|}
\hline Elemento & $\begin{array}{c}\text { Valor } \\
\text { razonable }\end{array}$ & $\begin{array}{c}\text { Base } \\
\text { fiscal }\end{array}$ & $\begin{array}{c}\text { Diferencia } \\
\text { temporaria }\end{array}$ & $\begin{array}{c}\text { Activos/Pasivos por } \\
\text { impuestos diferidos }\end{array}$ \\
\hline Activos no corrientes. Terrenos & 360.000 & 280.000 & $\begin{array}{c}80.000 \\
\text { diferencia temporaria } \\
\text { imponible) }\end{array}$ & $\begin{array}{c}80.000 \times 0,3=24.000 \\
\text { Pasivo por impuesto } \\
\text { diferido }\end{array}$ \\
\hline Activos no corrientes. Edificios & 130.000 & 150.000 & $\begin{array}{c}20.000 \\
\text { (diferencia temporaria } \\
\text { deducible) }\end{array}$ & $\begin{array}{c}20.000 \times 0,3=6.000 \\
\text { Activo por impuesto } \\
\text { diferido }\end{array}$ \\
\hline Pasivos no corrientes & 180.000 & 195.000 & $\begin{array}{c}15.000 \\
\text { diferencia temporaria } \\
\text { imponible) }\end{array}$ & $\begin{array}{c}15.000 \times 0,3=4.500 \\
\text { Pasivo por impuesto } \\
\text { diferido }\end{array}$ \\
\hline
\end{tabular}

DETERMINACIÓN DEL VALOR RAZONABLE DE LOS ACTIVOS Y PASIVOS IDENTIFICABLES ADQUIRIDOS EN LA FECHA DE ADQUISICIÓN INCLUYENDO LOS EFECTOS IMPOSITIVOS

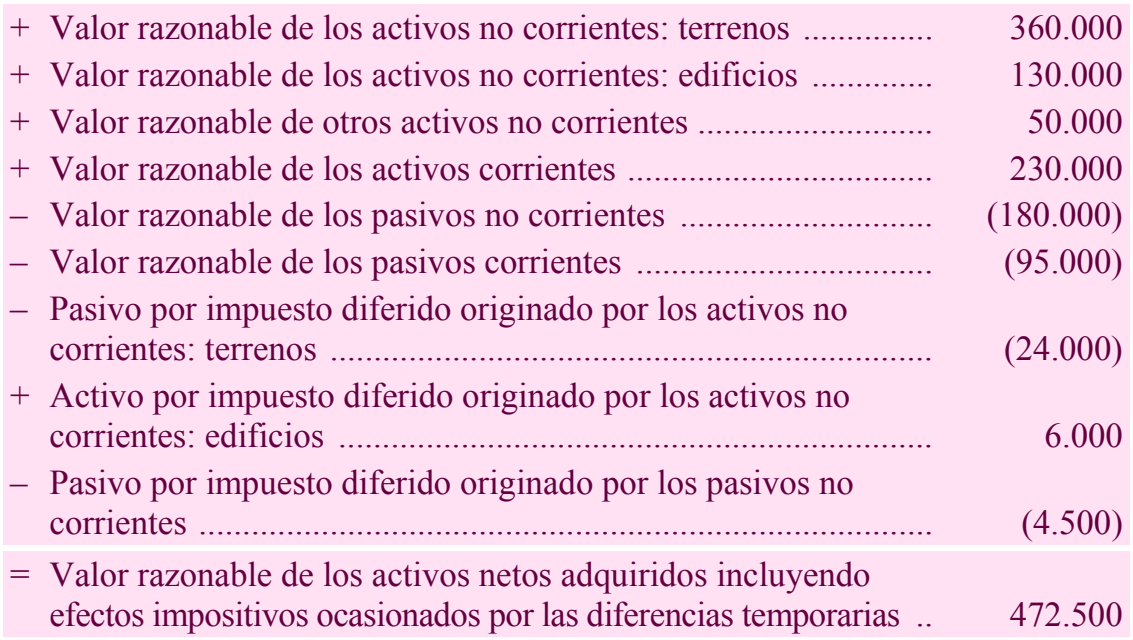

\section{DETERMINACIÓN DE LA DIFERENCIA DE LA COMBINACIÓN DE NEGOCIOS}

+ Coste de la combinación de negocios

- Valor razonable de los activos y pasivos identificables adquiridos en la fecha de adquisición

Fondo de comercio de la combinación

\section{CONTABILIZACIÓN DE LA COMBINACIÓN DE NEGOCIOS EN LA SOCIEDAD GAMESA}

Tanto el gasto o el ingreso por impuesto corriente como diferido, se inscribirán en la cuenta de pérdidas y ganancias. No obstante, si hubiesen surgido a causa de una combinación de negocios, se reconocerán con cargo o abono al fondo de comercio o como ajuste al exceso que suponga la participación de la empresa adquirente en el valor razonable neto de los activos y pasivos identificables de la empresa adquirida, sobre el coste de la combinación: 


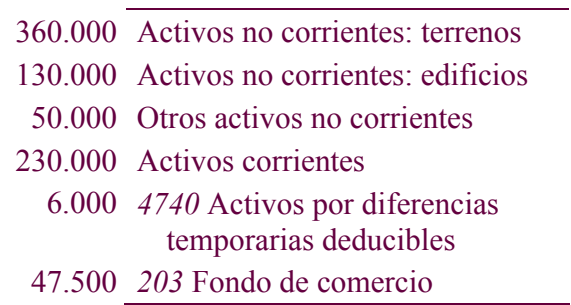

\begin{tabular}{|c|c|}
\hline Pasivos no corrientes & 180.000 \\
\hline Pasivos corrientes & 95.000 \\
\hline $\begin{array}{l}479 \text { Pasivos por diferencias } \\
\text { temporarias imponibles }\end{array}$ & 28.500 \\
\hline $\begin{array}{l}572 \text { Bancos e instituciones de } \\
\text { crédito c/c, euros }\end{array}$ & 520.000 \\
\hline
\end{tabular}

De acuerdo con el principio de prudencia sólo se reconocerán activos por impuesto diferido en la medida en que resulte probable que la empresa disponga de ganancias fiscales futuras que permitan la aplicación de estos activos. Cuando la diferencia temporaria deducible haya surgido por inversiones en empresas dependientes, asociadas o negocios conjuntos, sólo se reconocerá un activo por impuesto diferido si se espera que dicha diferencia revierta en un futuro previsible y sea probable que la empresa disponga de ganancias fiscales futuras en cuantía suficiente.

En general, se reconocerá un pasivo por impuesto diferido por todas las diferencias temporarias imponibles, a menos que éstas hubiesen surgido del reconocimiento inicial de un fondo de comercio. Sin embargo, los pasivos por impuesto diferido relacionados con un fondo de comercio, se registrarán siempre que no hayan surgido de su reconocimiento inicial.

\section{COMBINACIONES DE NEGOCIOS REALIZADAS POR ETAPAS}

Las combinaciones de negocios realizadas por etapas son aquellas en las que la empresa adquirente obtiene el control de la adquirida mediante varias transacciones independientes realizadas en fechas diferentes; tal es el caso de la formación de un grupo mediante la compra sucesiva de instrumentos de patrimonio que concedan derechos de voto.

Estas combinaciones se contabilizarán aplicando el método de adquisición con las siguientes precisiones:

a) En la determinación del coste de la combinación de negocios, se considerará el coste de cada una de las transacciones individuales.

b) En cada una de las transacciones individuales se determinará el fondo de comercio o diferencia negativa por comparación entre el coste de las inversiones correspondientes y la participación de la adquirente en los valores razonables de los activos, pasivos y pasivos contingentes identificables de la entidad adquirida.

c) La diferencia entre el valor razonable de la participación de la adquirente en los elementos identificables de la empresa adquirida 
en cada una de las fechas de las transacciones individuales y su valor razonable en la fecha de adquisición se reconocerá directamente en las reservas de la empresa.

En la fecha de adquisición, aquella en la que la adquirente obtiene el control de la adquirida, la adquirente debe reconocer por su valor razonable los activos, pasivos y pasivos contingentes de la adquirida, y determinar la diferencia de la combinación, para ello considerará que:

- El coste de la combinación será igual a la suma del coste de cada una de las transacciones individuales.

- La diferencia de la combinación será el resultado de la suma de la diferencia entre el coste de cada transacción individualmente considerada y el valor razonable neto de la entidad adquirida comprado en cada una de las transacciones.

Como en una adquisición realizada en una única transacción, los intereses minoritarios se reconocen por su participación en el valor razonable de los activos, pasivos y pasivos contingentes identificables.

Si con anterioridad, dicha inversión hubiera sido calificada como disponible para la venta, los ajustes valorativos que luzcan en el patrimonio neto deberán reclasificarse a la partida de reservas que recoja la diferencia descrita en el párrafo anterior.

Otra cuestión diferente se produce cuando una vez alcanzado el control se efectúan nuevas adquisiciones, cuestión pendiente de abordar por el PGC y por las Normas Internacionales de Contabilidad ${ }^{5}$. Estas inversiones adicionales cuando ya se posee el control no pueden considerarse combinaciones de negocios y no pueden reconocerse contablemente por el método de la adquisición. Dado que las entidades participantes en la operación no son independientes, sino partes vinculadas, el precio de la

5 La regulación actual española (RD 1815/1991), establece que cuando una entidad dominante incremente su porcentaje de participación en una dependiente deberá reconocer la diferencia entre el coste de la participación y el valor de mercado del porcentaje de los elementos de la dependiente adquirido como una nueva diferencia de consolidación, ya sea un fondo de comercio o una diferencia negativa de consolidación. Por tanto, estas operaciones tienen el mismo tratamiento contable que la primera consolidación, es decir, en el RD 1815/1991, esta operación se considera que es una nueva combinación de negocios. 
transacción difícilmente será una estimación fiable del precio de mercado de los instrumentos de capital; será más bien un precio fijado en términos de conveniencia para la entidad dominante.

Por otro lado, el reflejo contable del fondo de comercio generado, en su caso, por las citadas adquisiciones adicionales cuando ya se posee el control, supondría contabilizar un fondo de comercio generado internamente al grupo, cuestión que queda expresamente prohibida por el PGC y las Normas Internacionales de Contabilidad.

Por último, el fondo de comercio se ha de calcular referido a la fecha de adquisición siendo considerada ésta como la fecha en la que se obtiene el control sobre el negocio adquirido. En las compras adicionales ya se posee el control por lo que no cabe considerar las respectivas fechas de intercambio como fechas de adquisición y no se podrían calcular nuevas diferencias de combinación.

Las inversiones adicionales cuando ya se posee el control suponen la compra de instrumentos de capital de entidades del grupo y debe recibir, a nuestro juicio, el mismo tratamiento que la compra de acciones propias en una entidad individual que únicamente modifica la estructura accionarial del grupo, pero en la que no procede reconocer ningún resultado para la entidad dominante.

El tratamiento contable correcto y compatible con lo establecido por las Normas Internacionales de Contabilidad (concretamente la NIC 32) es el siguiente:

- Variación de las Reservas reconocidas en los estados financieros consolidados, por la diferencia entre el precio pagado por los instrumentos de capital adquiridos y el valor teórico contable del porcentaje de los intereses minoritarios que se da de baja del balance consolidado.

- Reducción de los intereses minoritarios, por el valor teórico del porcentaje de instrumentos de capital adquirido en la operación.

\section{Ejemplo $\mathrm{n}^{0}$ 9.- Combinaciones de negocios realizadas por etapas}

Las sociedades A y B forman un grupo, pues la sociedad A posee el $70 \%$ del capital y de los derechos de voto de la sociedad B. La adquisición de la citada participación se ha realizado a través de varias operaciones sucesivas de compra de títulos, en las siguientes condiciones: 


\begin{tabular}{|l|c|c|}
\hline Fecha de adquisición & Porcentaje adquirido & Precio de adquisición \\
\hline $31-12-X 0$ & 30 & 40 \\
\hline $31-12-X 1$ & 20 & 35 \\
\hline $31-12-X 2$ & 20 & 50 \\
\hline & $\mathbf{7 0}$ & $\mathbf{1 2 5}$ \\
\hline
\end{tabular}

A las fechas indicadas la sociedad B presentaba la siguiente composición en su patrimonio neto:

\begin{tabular}{|l|c|c|c|}
\hline & $\mathbf{3 1 - 1 2 - X 0}$ & $\mathbf{3 1 - 1 2 - X 1}$ & $\mathbf{3 1 - 1 2 - X \mathbf { X }}$ \\
\hline Capital social & 100 & 100 & 100 \\
\hline Reservas & 20 & 50 & 100 \\
\hline & $\mathbf{1 2 0}$ & $\mathbf{1 5 0}$ & $\mathbf{2 0 0}$ \\
\hline
\end{tabular}

En las fechas de compra de las sucesivas participaciones coincidia el valor contable de los activos y pasivos de la sociedad B con sus valores razonables.

Entre las sociedades $A$ y $B$ no se han realizado operaciones internas, ni se ha llevado a cabo reparto de dividendos.

Se pide:

1) Calcular las diferencias de la combinación de negocios.

2) Asiento de eliminación inversión-patrimonio neto correspondiente al ejercicio X2.

\section{Solución.-}

1) Como se trata de una combinación de negocios efectuada por etapas, hay que calcular diferencias por cada operación de compra de títulos, en cada fecha de intercambio, independientemente de que se posea el control o no en la fecha de las compras respectivas.

Como la sociedad B pasa a ser dependiente de la sociedad A, el 31-12-X2, esa es la fecha de adquisición y de la primera consolidación, pero el cálculo de las diferencias de consolidación se desglosará en tres partes correspondientes a cada operación de compra de títulos realizada hasta esa fecha.

CÁlCULO DE LA DIFERENCIA DE CONSOLIDACIÓN POR LA INVERSIÓN REALIZADA EL 31-12-X0:

Valor contable de la participación en la sociedad B adquirida el 31-12-X0

- Parte proporcional del valor razonable del patrimonio neto de la sociedad B al 31-12-X0: 30\% s/120

$=$ Diferencia positiva de consolidación

CÁLCULO DE LA DIFERENCIA DE CONSOLIDACIÓN POR LA INVERSIÓN REALIZADA EL 31-12-X1:

Valor contable de la participación en la sociedad B adquirida el 31-12-X1

- Parte proporcional del valor razonable del patrimonio neto de la sociedad B al 31-12-X1: $20 \% \mathrm{~s} / 150$

Diferencia positiva de consolidación 
CÁLCULO DE LA DIFERENCIA DE CONSOLIDACIÓN POR LA INVERSIÓN REALIZADA EL 31-12-X2:

Valor contable de la participación en la sociedad B adquirida el 31-12-X2

- Parte proporcional del valor razonable del patrimonio neto de la sociedad B al 31-12-X2: $20 \% \mathrm{~s} / 200$

Diferencia positiva de consolidación

Dichas diferencias positivas se consideran un fondo de comercio que figurará en el activo del Balance consolidado.

Cálculo de los intereses minoritarios a 31-12-X2:

$$
(1-0,70) \times 200=0,30 \times 200=60
$$

Cálculo de las reservas ganadas en $\mathrm{B}$ :

$$
0,30 \times(150-120)+0,50 \times(200-150)=9+25=34
$$

2) Asiento de eliminación inversión-patrimonio neto correspondiente a la consolidación del ejercicio X2:

$$
\begin{aligned}
100 & \text { Capital (B) } \\
100 & \text { Reservas (B) } \\
19 & \text { Fondo de comercio }
\end{aligned}
$$

(1)

a Participación en empresas del grupo

a $\operatorname{Reservas}(\mathrm{A})$

a Intereses minoritarios $\quad 60$

Los activos y pasivos de la sociedad dependiente se reconocen en la fecha de adquisición (31-12-X2) por sus valores razonables (que en este caso coinciden con los valores contables).

La cuenta Participación en empresas del grupo se da de baja por un importe equivalente al coste de la combinación que será la suma de los costes de las transacciones individuales.

Se reconoce el fondo de comercio surgido en las diferentes transacciones de intercambio.

\section{CONTABILIDAD INICIAL PROVISIONAL}

Si en la fecha de cierre del ejercicio en que se ha producido la combinación de negocios no se pudiese concluir el proceso de valoración necesario para aplicar el método de adquisición, las cuentas anuales se elaborarán utilizando valores provisionales.

Los valores provisionales serán ajustados en el periodo necesario para obtener la información requerida para completar la 
contabilización inicial. Dicho periodo en ningún caso será superior a un año desde la fecha de la adquisición.

Para que puedan realizarse los ajustes comentados, la entidad adquirente debe demostrar que la nueva información proporciona una mejor evidencia del valor razonable de los bienes en la fecha de adquisición. Esto es, la nueva información debe proporcionar una mejor evidencia sobre los hechos y circunstancias que existían en esa fecha que, de haberse conocido, habrían tenido un impacto en el reconocimiento y valoración de los bienes adquiridos en la combinación de negocios. Por lo tanto, nueva información que reflejase sucesos posteriores a la fecha de adquisición no llevaría a realizar cambios en la contabilización inicial. Por ejemplo, en la fecha de adquisición el valor razonable de una inversión inmobiliaria de la adquirida se estima en $80.000 €$. Seis meses después de la adquisición la situación real de mercado inmobiliario empeora significativamente, debido a una crisis de carácter internacional, de forma que el valor del inmueble cae hasta 60.000€. El descenso en el valor se relaciona con un suceso posterior a la adquisición y, consecuentemente, no se reconoce ningún ajuste en el valor de los terrenos adquiridos (o en el fondo de comercio). En vez de ello, se evalúa el deterioro de la inversión inmobiliaria y cualquier pérdida resultante se reconoce en resultados.

Los ajustes que se reconozcan para completar la contabilización inicial se realizarán de forma retroactiva, es decir, de forma tal que los valores resultantes sean los que se derivarían de haber tenido inicialmente la información que se incorpora. Por lo tanto:

- Los ajustes al valor inicial de los activos y pasivos identificables se considerarán realizados en la fecha de adquisición.

- El valor del fondo de comercio o de la diferencia negativa se corregirá, con efectos desde la fecha de adquisición, por un importe igual al ajuste que se realiza al valor inicial de los activos y pasivos identificables.

- La información comparativa incorporará los ajustes.

Transcurrido el período mencionado en este apartado, sólo se practicarán ajustes a las valoraciones iniciales cuando: 
- Proceda ajustar las contraprestaciones adicionales que dependan de eventos futuros o del cumplimiento de ciertas condiciones.

- Se reconozcan activos por impuesto diferido no contabilizados previamente.

- Proceda corregir errores conforme a lo establecido en la norma de registro y valoración $n^{\circ} 22$.

Si una entidad sólo ha podido determinar el valor razonable de los activos y pasivos identificables de una adquirida con criterios provisionales al final del periodo en que ha ocurrido la combinación de negocios, debe revelar información sobre este hecho junto con una explicación de las razones.

\section{Ejemplo n⿳0 10.-}

La entidad CATAPLASMA adquirió, el 1 de junio de X1, en una combinación de negocios a la entidad FROMASA. Al valorar los activos, pasivos y pasivos contingentes de esta entidad se solicitó a un experto independiente la tasación de una instalación especializada, que se estimó que tenía una vida útil de 30 años; al final del ejercicio X1 la tasación no se había terminado.

La sociedad CATAPLASMA, como se establece en la norma de registro y valoración $n^{\circ} 19$ del PGC, contabilizó la combinación de negocios con valores provisionales, reconociendo en sus cuentas anuales la instalación especializada por $245.000 €$ (valor residual de 20.000€). El fondo de comercio derivado de la combinación ascendió en la fecha de la compra a $125.000 €$.

El 1 de enero de X2 la sociedad CATAPLASMA recibió la tasación del experto independiente que estimó que el valor razonable del activo en la fecha de adquisición era $290.000 €$, con un valor residual de 20.000€.

Se pide: La contabilización de los ajustes contables derivados de completar la combinación de negocios.

\section{Solución.-}

La sociedad CATAPLASMA contabilizó en la fecha de adquisición la combinación de negocios utilizando valores provisionales. Como el 1 de enero de X2 se conoce la valoración definitiva de la instalación especializada, que difiere de la valoración provisional, procede rectificar la valoración del citado elemento en las cuentas de CATAPLASMA y ajustar el fondo de comercio resultante de la combinación de negocios.

Determinación de la amortización practicada por la sociedad CATAPLASMA hasta el 1-1-X2: 


$$
A=\frac{(245.000-20.000)}{30} \times \frac{6}{12}=3.750
$$

Determinación de la amortización que habría tenido que realizar la sociedad CATAPLASMA hasta el 1-1-X2 de haber conocido el valor definitivo:

$$
A=\frac{(290.000-20.000)}{30} \times \frac{6}{12}=4.500
$$

Determinación del ajuste en el fondo de comercio:

\begin{tabular}{|l|c|c|c|}
\hline & $\begin{array}{c}\text { Valores } \\
\text { provisionales }\end{array}$ & $\begin{array}{c}\text { Valores } \\
\text { definitivos }\end{array}$ & $\begin{array}{c}\text { Ajuste } \\
\text { contable }\end{array}$ \\
\hline + Coste de la instalación especializada & 245.000 & 290.000 & 45.000 \\
\hline - amortización acumulada & $(3.750)$ & $(4.500)$ & $(750)$ \\
\hline = Valor en libros del edificio & 241.250 & 285.500 & 44.250 \\
\hline Fondo de comercio & 125.000 & 80.000 & $(45.000)$ \\
\hline
\end{tabular}

Ajuste contable:

\begin{aligned} & 45.000 Edificios \\ & 750 Reservas \\ & \hline\end{aligned}

(1)

a $\overline{\text { Fondo de comercio }} \quad 45.000$

a Amortización acumulada $\quad 750$

En el ajuste se revalorizan las instalaciones especializadas por la diferencia entre el valor provisional y el definitivo, se reduce el fondo de comercio procedente de la combinación de negocios por el mismo importe, se ajusta la amortización de las instalaciones, realizada desde la fecha de adquisición hasta la fecha de la valoración definitiva, y se reduce el resultado declarado por CATAPLASMA durante el ejercicio X1.

\section{ADQUISICIONES INVERSAS}

Las adquisiciones inversas son aquellas combinaciones de negocios en las que la entidad adquirente no es la que emite instrumentos de capital, sino aquella que adquiere los instrumentos de capital de otra entidad participante en la combinación. Por tanto, las adquisiciones inversas se caracterizan porque la adquirida o dependiente legal es la dominante o adquirente contable, y la adquirente o dominante legal es la adquirida o dependiente legal.

La NIIF 3, en la actualidad sólo permite que las combinaciones de negocios se traten contablemente de acuerdo con el método de compra, que supone que todas las combinaciones son adquisiciones $\mathrm{y}$, por tanto, existe una entidad adquirente y otra, u otras, adquiridas. 
Normalmente, la entidad adquirente es aquella que para realizar la combinación de negocios emite instrumentos de capital. Pero en ciertas ocasiones, emite un número tan elevado de instrumentos de capital, que el control de la entidad resultante de la combinación pasa a ser de los antiguos propietarios de la entidad adquirida, es el caso de las adquisiciones inversas.

El tratamiento contable de las adquisiciones inversas afecta a la distribución del coste de la combinación de negocios entre los activos identificables, pasivos y pasivos contingentes de la entidad adquirida, y no a consolidaciones posteriores a la fecha de adquisición de la combinación.

En las adquisiciones inversas el coste de la combinación se supone que lo soporta la adquirida desde el punto de vista legal y, por tanto, se tiene que estimar sobre la base de:

- El precio de cotización de los instrumentos de capital de la adquirida legal: el coste se determinará a partir del número de instrumentos de capital que la adquirida legal hubiera tenido que emitir para que los propietarios de la adquirente legal posean el mismo porcentaje de participación en la entidad resultante de la combinación que la participación que poseen en la misma al final de la adquisición inversa.

- El precio de cotización de todos los instrumentos de capital de la adquirente legal emitidos antes de la combinación: se utilizará para determinar el coste de la combinación si el precio de cotización de los instrumentos de capital de la adquirida legal no es claramente evidente. los estados financieros consolidados elaborados tras una adquisición inversa se emitirán bajo la denominación de la dominante legal, pero se describirán en las notas como una continuación de los estados financieros de la dependiente legal, por tanto:

- Los elementos de la dependiente legal se reconocerán y valorarán por el valor en libros que tenían antes de la combinación.

- El importe de los instrumentos de capital emitidos que figure en los estados financieros consolidados será el importe de los instrumentos de capital de la dependiente legal antes de la adquisición inversa más el coste de la combinación de negocios.

- Las reservas y otros componentes del patrimonio neto que figure en los estados financieros consolidados será el de la 
dependiente legal, estructurados de la misma de acuerdo con la estructura utilizada por la dominante legal.

- Se presentará información comparativa de la dependiente legal.

En las adquisiciones inversas, el importe de los intereses minoritarios recogerá el porcentaje que representan en el patrimonio neto los propietarios de la entidad adquirida legal que no han comprado instrumentos de capital de la dominante legal. Esto es así, porque estos solamente participan en el patrimonio neto de la dependiente legal, y no en el de la entidad resultante de la combinación.

\section{NEGOCIOS}

\section{INFORMACIÓN EN MEMORIA SOBRE COMBINACIONES DE}

Las combinaciones de negocios son operaciones de una gran trascendencia en la vida de una entidad; por ello, el PGC exige la incorporación en la memoria de un elevado volumen de información acerca de las mismas para poder evaluar su naturaleza y el efecto financiero que producen.

1. La empresa adquirente indicará, para cada una de las combinaciones de negocios que haya efectuado durante el ejercicio, la siguiente información:

a) Los nombres y descripciones de las empresas o negocios que se combinen.

b) La fecha de adquisición.

c) La forma jurídica empleada para llevar a cabo la combinación.

d) Los motivos por los que se realiza la operación, así como una descripción de los factores que dan lugar al reconocimiento del fondo de comercio.

e) El coste de la combinación y una descripción de los componentes del mismo, desagregando por categorías de elementos tales como:

- Efectivo.

- Otros activos materiales o intangibles, tales como un negocio o empresa dependiente de la adquirente. 
- Pagos contingentes.

- Instrumentos de deuda.

- Participación en el patrimonio del adquirente, incluyendo el número de instrumentos de patrimonio emitidos o a emitir y el método para estimar su valor razonable.

- Las participaciones previas en el patrimonio de la empresa adquirida que no hayan dado lugar al control de la misma, en las combinaciones de negocio por etapas.

f) Los importes reconocidos, en la fecha de adquisición, para cada clase de activos y pasivos de la empresa adquirida, indicando aquellos que de acuerdo con la norma de registro y valoración no se recogen por su valor razonable.

g) El importe máximo potencial de los pagos futuros que la adquirente pudiera estar obligada a realizar conforme a las condiciones de la adquisición, o la circunstancia de que tal importe no existe, si así fuera.

h) Respecto al fondo de comercio que pueda haber surgido en las combinaciones de negocio, la empresa deberá suministrar la información siguiente:

- Para cada combinación de negocios que se haya realizado en el ejercicio, se expresará la cifra del fondo de comercio, desglosándose las correspondientes a las distintas combinaciones de negocios.

Tratándose de combinaciones de negocios que individualmente carezcan de importancia relativa, la información anterior se mostrará de forma agregada.

Esta información también deberá expresarse para las combinaciones de negocios efectuadas entre la fecha de cierre de las cuentas anuales y la de su formulación, a menos que no sea posible, señalándose, en este caso, las razones por las que esta información no puede proporcionarse.

- La empresa realizará una conciliación entre el importe en libros del fondo de comercio al principio y al final del ejercicio, mostrando por separado:

- El importe bruto del mismo y las correcciones valorativas por deterioro acumuladas al principio del ejercicio. 
- El fondo de comercio adicional reconocido durante el periodo, diferenciando el fondo de comercio incluido en un grupo enajenable de elementos que se haya clasificado como mantenido para la venta, de acuerdo con las normas de registro y valoración. Asimismo se informará sobre el fondo de comercio dado de baja durante el periodo sin que hubiera sido incluido previamente en ningún grupo enajenable de elementos clasificado como mantenido para la venta.

- Los ajustes que procedan del reconocimiento posterior de activos por impuesto diferido efectuado durante el ejercicio.

- Las correcciones valorativas por deterioro reconocidas durante el ejercicio.

- Cualesquiera otros cambios en el importe en libros durante el ejercicio, y

- El importe bruto del fondo de comercio y las correcciones valorativas por deterioro acumuladas al final del ejercicio.

- Descripción de los factores que hayan contribuido al registro del fondo de comercio así como, se justificará e indicará el importe del fondo de comercio atribuido a cada unidad generadora de efectivo.

- Para cada pérdida por deterioro de cuantía significativa del fondo de comercio, se informará de lo siguiente:

- Descripción de la unidad generadora de efectivo que incluya el fondo de comercio así como otros inmovilizados intangibles o materiales y la forma de realizar la agrupación para identificar una unidad generadora de efectivo cuando sea diferente a la llevada a cabo en ejercicios anteriores.

- Importe, sucesos y circunstancias que han llevado al reconocimiento de una corrección valorativa por deterioro.

- Criterio empleado para determinar el valor razonable menos los gastos de venta, en su caso, y

- Si el método empleado fuera el valor en uso, se señalará el tipo o tipos de actualización utilizados en las estimaciones actuales y en las anteriores, una descripción de las hipótesis clave sobre las que se han basado las proyecciones de flujos de efectivo y de cómo se han determinado sus valores, el período que abarca la proyección de los flujos de efectivo y la tasa de crecimiento de éstos a partir del quinto año. 
- Respecto a las pérdidas por deterioro agregadas para las que no se revela la información señalada en el número anterior, los principales sucesos y circunstancias que han llevado al reconocimiento de tales correcciones valorativas por deterioro.

- Las hipótesis utilizadas para la determinación del importe recuperable de los activos o de las unidades generadoras de efectivo.

- Cuando el valor en libros del fondo de comercio o de otros inmovilizados intangibles con vida útiles indefinidas se atribuya a varias unidades generadoras de efectivo y el importe asignado a cada unidad no sea significativo en comparación con el valor en libros total de estos elementos en la empresa, se revelará este hecho y el importe agregado asignado a estas unidades.

- Asimismo, si el importe recuperable de algunas de estas unidades está basado en las mismas hipótesis y la suma del valor en libros del fondo de comercio o de los inmovilizados intangibles con vida útil indefinida atribuido a esas unidades generadoras de efectivo fuera significativo en comparación con el valor en libros total de estos elementos en la empresa, se indicará:

- El valor en libros agregado del fondo de comercio y de los inmovilizados intangibles con vida útil indefinida atribuidos a esas unidades, $y$

- Una descripción de las hipótesis clave, señalando si los valores reflejan la experiencia pasada de la empresa o fuentes externas de información.

i) En las combinaciones de negocios en las que el coste de la combinación resulte inferior al valor de los activos identificables adquiridos menos el de los pasivos asumidos, el importe y la naturaleza de cualquier exceso que se reconozca en la cuenta de pérdidas y ganancias de acuerdo con lo establecido en la norma de registro y valoración y la partida en la que figure. Asimismo, en su caso, se describirán los activos intangibles que no hayan podido ser registrados por no poder calcularse su valoración por referencia a un mercado activo.

j) En las combinaciones de negocio en las cuales existiese una relación previa entre adquirente y adquirido, en la fecha de adquisición, se señalará la naturaleza de dicha relación y, en su 
caso, la valoración del importe para liquidar dicha relación previa, el método utilizado para su determinación y cualquier resultado reconocido como consecuencia de dicha liquidación así como la partida en la que figure.

2. La información requerida en el apartado anterior se revelará de forma agregada para las combinaciones de negocios, efectuadas durante el ejercicio económico, que individualmente carezcan de importancia relativa.

Adicionalmente, la empresa adquirente proporcionará la información contenida en el apartado anterior para cada una de las combinaciones de negocios efectuadas o en curso entre la fecha de cierre de las cuentas anuales y la de su formulación, a menos que esto no sea posible. En este caso se señalarán las razones por las que esta información no puede ser proporcionada.

3. La empresa adquirente revelará, de forma separada para cada combinación de negocios efectuada durante el ejercicio, o agregadamente para las que carezcan individualmente de importancia relativa, la parte de los ingresos y el resultado imputable a la combinación desde la fecha de adquisición. También indicará los ingresos y el resultado del ejercicio que hubiera obtenido la empresa resultante de la combinación de negocios bajo el supuesto de que todas las combinaciones de negocio realizadas en el ejercicio se hubiesen efectuado en la fecha de inicio del mismo.

En el caso de que esta información no pudiese ser suministrada, se señalará este hecho y se motivará.

4. Se indicará la siguiente información en relación con las combinaciones de negocios efectuadas durante el ejercicio o en los ejercicios anteriores:

a) Si el importe reconocido en cuentas se ha determinado provisionalmente, se señalarán los motivos por los que el reconocimiento inicial no es completo, los activos adquiridos y compromisos asumidos para los que el periodo de valoración está abierto y el importe y naturaleza de cualquier ajuste en la valoración efectuado durante el ejercicio. 
b) Una descripción de los hechos o circunstancias posteriores a la adquisición que han dado lugar al reconocimiento durante el ejercicio de impuestos diferidos adquiridos como parte de la combinación de negocios.

c) El importe y una justificación de cualquier ganancia o pérdida reconocida en el ejercicio que esté relacionada con los activos adquiridos o pasivos asumidos y sea de tal importe, naturaleza o incidencia que esta información sea relevante para comprender las cuentas anuales de la empresa resultante de la combinación de negocios.

\section{BIBLIOGRAFÍA}

Calvo González-ValLinas, J. (2008) "Las combinaciones de negocios en el Plan General de Contabilidad", Técnica Contable, $\mathrm{n}^{\circ}$ 706, marzo, pp. 99-110.

CASILlas Cuevas, A. (2007) "Análisis del concepto de grupo consolidable bajo el prisma de la normativa contable nacional e internacional", Técnica Contable, $\mathrm{n}^{\circ} 700$, septiembre, pp. 38-43.

Corona Romero, E. y V. Bejarano VÁzQuez (2007) "IASB, ¿Un cambio de enfoque en la consolidación de estados financieros?", Partida Doble, $\mathrm{n}^{\circ}$ 189, junio, pp. 52-65.

-, J. Talavero Sanguino, f. García Martínez, Á. Monzón Sánchez, R. López Galindo, J. Clavo González-Vallinas y J. VARela Cruzeiro (2005) Aplicación de las normas internacionales de contabilidad adoptadas por la Unión Europea (NICes). Valencia: CISS, pp. 421-477.

INTERNATIONAL ACCOUNTING STANDARDS BOARD (2006) Normas Internacionales de Información Financiera (NIIF), texto completo de las Normas Internacionales de Información Financiera emitidas a 1 de enero de 2006, traducción al español publicada por CISS-PRAXIS con la autorización de la IASCF.

JIMÉNEZ CARDOSO, S.M. (2007) "Las combinaciones de negocios en el borrador del PGC", Partida Doble, n 193, noviembre, pp. 10-25.

KPMG INTERNATIONAL FINANCIAL REPORTING GROUP (2006) Las NIIF comentadas. Guía práctica de KPMG para comprender las Normas Internacionales de Información Financiera. Navarra: Thomson-Aranzadi, pp. 82-124. 
LEY $16 / 2007$, de 4 de julio, de reforma y adaptación de la legislación mercantil en materia contable para su armonización internacional con base en la normativa de la Unión Europea (BOE del 5 de julio de 2007).

Otal Franco, S.H. y R. SeRrano García (2005) "Las combinaciones de negocios en las Normas Internacionales de Información Financiera", Partida Doble, $\mathrm{n}^{\circ}$ 172, diciembre, pp. 74-89.

REAL DECRETO 1514/2007, de 16 de noviembre, por el que se aprueba el Plan General de Contabilidad (BOE del 20 de noviembre de 2007).

REAL DECRETO 1515/2007, de 16 de noviembre, por el que se aprueba el Plan General de Contabilidad de Pequeñas y Medianas Empresas y los criterios contables específicos para microempresas (BOE del 21 de noviembre de 2007).

Rubio MARTín, G. (2008) "Los nuevos retos de valoración de intangibles en combinaciones de negocios", Partida Doble, $\mathrm{n}^{\circ} 198$, abril, pp. 14-25.

SALVADOR MONTIEL, M.D. (2008) "Cómo aplicar el método de la adquisición en las combinaciones de negocios", Partida Doble, $\mathrm{n}^{\circ}$ 198, abril, pp. 26-41.

- (2006) "Normativa contable internacional y el fondo de comercio en las combinaciones de negocios", Estudios Financieros, n² 283, pp. 179-194. 